\title{
HIGH TEMPERATURE HIGH PRESSURE THERMODYNAMIC MEASUREMENTS FOR COAL MODEL COMPOUNDS
}

Semi-Annual Report 3/1/1998 to $9 / 30 / 1998$

Principal Author: Vinayak N. Kabadi

DOE Award No: DE-FG22-95PC95214--06

Submitting Organization: North Carolina A\&T State University Chemical Engineering Department Greensboro, North Carolina 27411

May 1, 2000

VAPOR-LIQUID EQUILIBRIUM DATA MEASUREMENT FOR ETHYLBENZENE-QUINOLINE SYSTEM 


\section{VAPOR-LIQUID EQUILIBRIUM APPARATUS:}

The Vapor Liquid Equilibrium measurement setup of this work was first established several years ago ${ }^{(1)}$. It is a flow type high temperature high pressure apparatus which was designed to operate below $500^{\circ} \mathrm{C}$ temperature and 2000 psia pressure.

Compared with the static method, this method has three major advantages: the first is that large quantity of sample can be obtained from the system without disturbing the equilibrium state which was established before; the second is that the residence time of the sample in the equilibrium cell is greatly reduced, thus decomposition or contamination of the sample can be effectively prevented; the third is that the flow system allows the sample to degas as it heats up since any non condensable gas will exit in the vapor stream, accumulate in the vapor condenser, and not be recirculated.

The first few runs were made with Quinoline-Tetralin system, the results were fairly in agreement with the literature data ${ }^{(2)}$. The former graduate student Amad used the same apparatus acquired the Benzene-Ethylbenzene system VLE data ${ }^{(3)}$. This work used basically the same setup (several modifications had been made) to get the VLE data of Ethylbenzene-Quinoline system.

\section{The Set-up:}

In Figure 1, the whole setup can be divided into four sections: feed section, equilibration section, sampling section, and control panel section. In the first three sections, all parts, tubing, and fittings are made of stainless steel (SS316). Most of the tubing used in the fabrication is $1 / 4$ " tubing except that the pressure sensing line is made of $3 / 8$ " tubing. The feed section consists of feed tank (1), positive displacement metering pump (2), one pulsation dampening bottle (not shown) and eighteen plug valves (not completely shown). The equilibration section consists of preheat oven (3), main oven (4), VLE cell (5), level indicator (6), liquid line control valve (23), vapor line control valve(24). As shown in Figure 1, in the preheat oven, the feed line tubing was shaped into 
circular coils, the liquid mixture can gain more residence time in the oven to get to the desired temperature. It is all the same with the main oven, the mixture passes through several coils of tubing in the main oven to reach the equilibrium temperature before it actually enters the VLE cell (the coils in the main oven were not shown in Figure 1).

The sampling section consists of two heat exchangers (11 and 12) to cool the two streams down (the vapor stream and the liquid stream). The liquid sample, vapor sample and the feed sample are obtained from the liquid sampling bottle (14), vapor sampling bottle (13) and feed sampling bottle (17) respectively. v6 and v7 are check valves, their function is to prevent the streams from back flowing. The control panel part consists of the main oven controller (16), preheat oven controller (15), process controller to control the pressure (7), process controller for the liquid level control in the cell (8), electronic chart recorder (9), pressure transducer (10) and a dozen of thermocouples (not shown). 


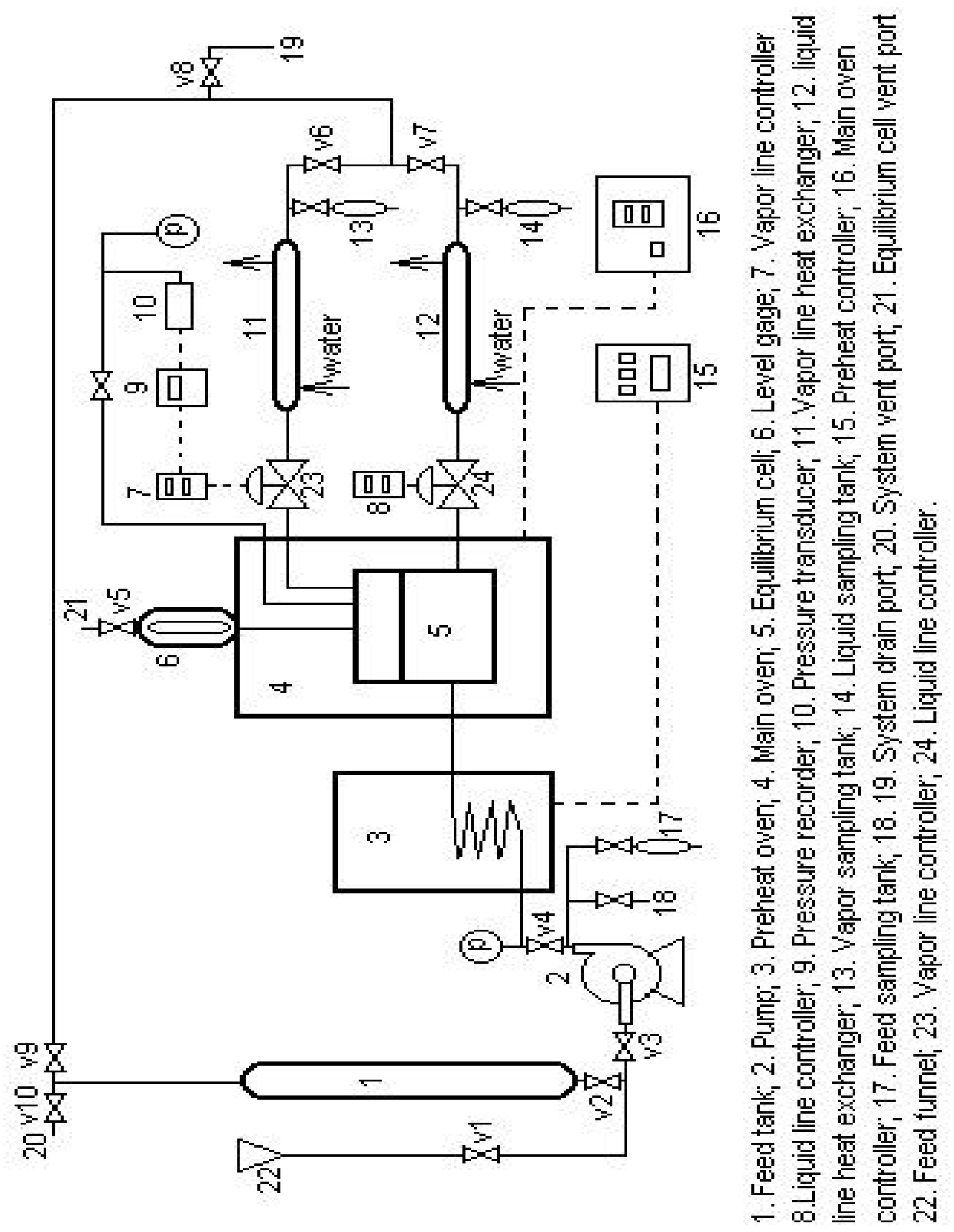

Figure 1: The VLE Flow Apparatus 
and a temperature digital display (not shown). All these elements were put one an wooden frame.

\section{The Level indicator:}

The critical part of the whole setup is the VLE cell. While it is relatively easy to get the temperature and pressure of the mixtures in the cell. The liquid level inside of the cell, which is a very important parameter to judge if the equilibrium state has been reached or not, is very tough to measure especially at high temperatures and pressures. Figure 2 shows the level probe used before. Two liner resistors were installed into the two probes respectively. Because the heat conductivity of liquid is much bigger than that of the vapor, different level of liquid in the cell may change the resistance of the resistors. Through the calibration process, the liquid level can be determined. However this method only works under $300^{\circ} \mathrm{C}$. Because we want to run the experiment all the way to $380^{\circ} \mathrm{C}$, a new method of determining the liquid level is necessary.

The basic idea of the new level indicator is quite straightforward. As is shown by Figure 3, a ball float (5) is put on the top of the liquid, then connect a thin wire (9) to the ball, the other end of the wire (13) goes through a 1/4" tubing (10) all the way into a level gage (3) on the top of the oven. The float will rise or drop along with the liquid level. By looking at the reading of the other end of the wire in the level gage, we can easily judge the liquid level inside the cell. By controlling the pressure control valve and the level control valve, the liquid level inside of the cell can be adjusted.

The problem came up with what material to be used to make the float ball and the thin wire. Because the VLE cell is too small for the commercial available floats. The 


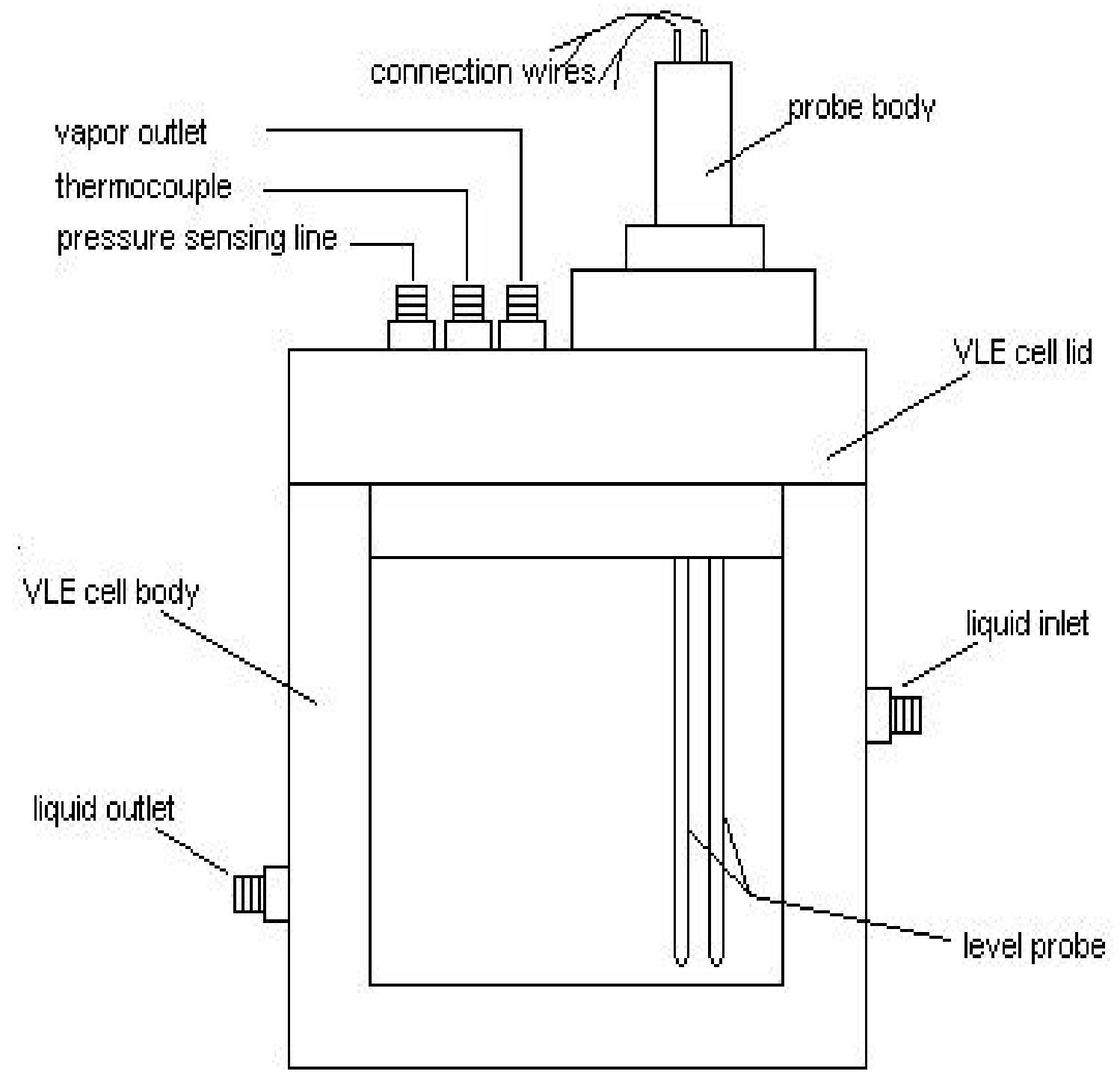

Figure 2. Conductivity Level Probe and Assembly 


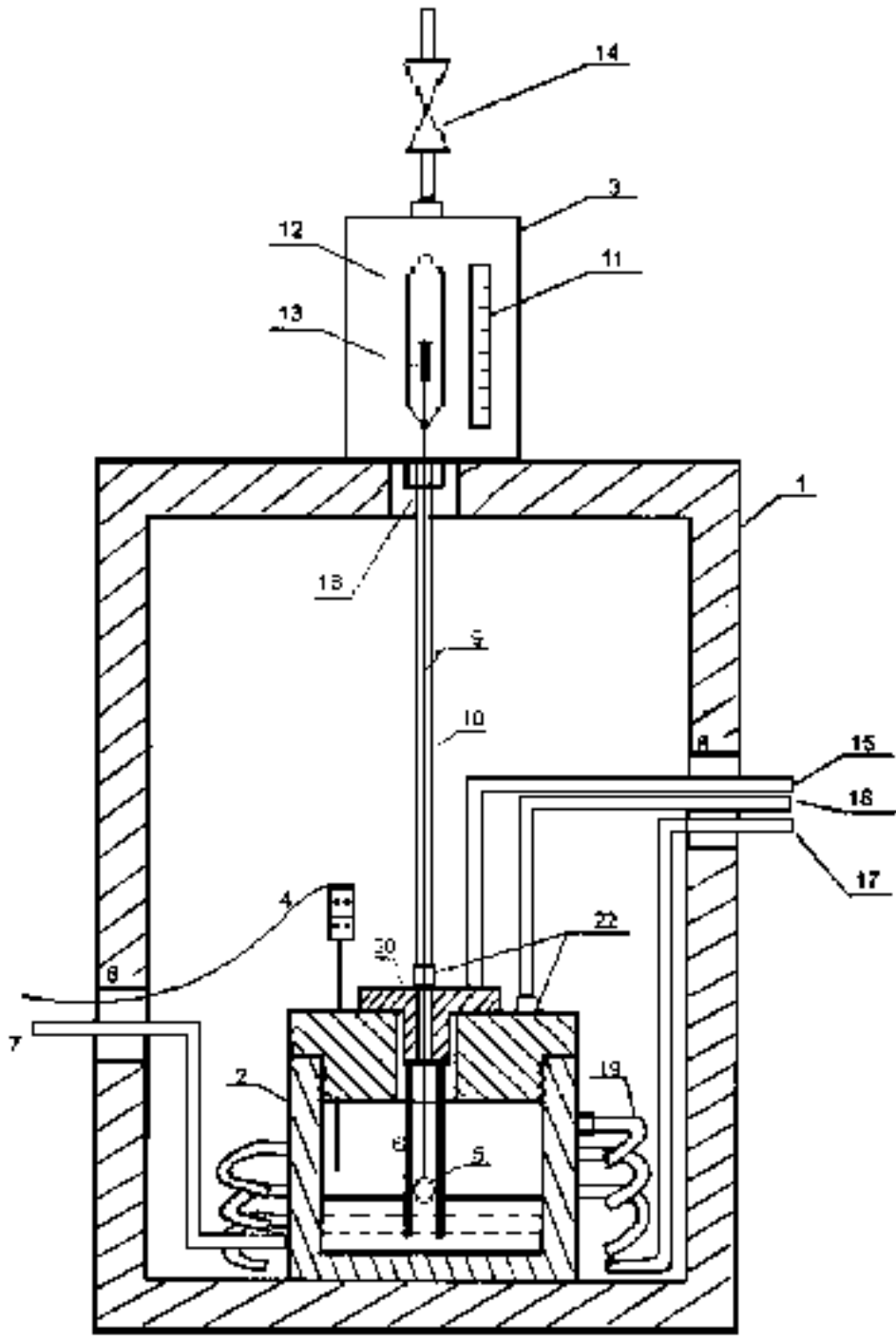

1. Main oven

2. VLE cell

3. Jerguson level gage (insulated)

4. Thermocouple

5. Glass ball float

6. Solid rod to hold the float from wandering

7. Liquid phase outlet tubing

8. Oven opening

9. Tungsten wire

10. $1 / 4$ " tubing

11. Ruler
12. Level gage window

13. Shinning material

14. Plug valve

15. Pressure sensing tube to transducer 16. Vapor phase outlet (1/4" tubing)

17. Feed inlet tubing (1/4")

18. $1 / 2$ " NPT male connector

19. $1 / 4$ " tubing coils

20. Flange

21. Top lid

22. Swagelok tubing fitting

Figure 3. Internal structure of the VLE cell and the oven 
diameter of the ball must be less than 1" because of the size of the cell, if the float is made by metals, it will either sink if the wall is thick enough to hold the pressure or collapse if the ball is made too light to be able to float over the liquid. Finally, glass was chosen to make the ball. The glass ball, though brittle, is strong enough to hold high compress pressure under high temperature, in the same time, it is light enough to float over the liquid. The selection of the wire is also kind of tricky, it must be quite rigid and also very light because the buoyancy of the float ball is very small. After all, tungsten was found to be the most rigid metal, and a piece of very thin tungsten wire was selected as part of the indicator.

\section{VLE PROCEDURES:}

Please refer to Figure 1. At first, about 3 Liters of premixed liquid mixture of Ethylbenzene and Quinoline were introduced to the feed tank (1) through the feed funnel (22). The mixture passes through a 60 micrometer and a 230 micrometer strainer before it is pumped by the positive displacement pump (2). The feed sample is withdrawn through the feed sample tank (17). After the pump, the feed mixture enters the coils located in the preheat oven (3). Obviously, the function of the coils in the preheat oven is to give the feed mixture much more residence time and much more heat transfer area in order for the mixture to gain the desired temperature before it exit the preheat oven. The mixture leaves the preheat oven at a temperature some $50^{\circ} \mathrm{C}$ to $100^{\circ} \mathrm{C}$ lower than the equilibrium temperature, then it enters the coils in the main oven (4). The main oven is set by the controller (16) to maintain the equilibrium temperature, the coils in the main oven is long enough for the feed mixture to reach the equilibrium temperature before it enters the equilibrium cell (5).

The equilibrium cell is the vital part of the whole setup. The phase equilibrium of the mixture is reached and maintained here. Once the mixture enters the cell, the mixture splits into vapor phase and liquid phase. By adjusting the liquid line control valve (24) and vapor line control valve (23), vapor phase and liquid phase leave the cell through vapor line and liquid line respectively. In the same time, an amount of liquid phase is 
accumulated and after all maintained at a certain level (i.e. 1-1.5”). The pressure of the system is measured both by the pressure gauge and the pressure transducer (10). The transducer sends 4-20 mv signal to the pressure controller (7) and the recorder (9). The recorder was carefully calibrated by a pressure gauge which has a resolution of 0.1 psia (refer to the appendix part) all the way up to 500 psia (gauge pressure). The controller(7) is a PID process controller which was calibrated to a resolution of 1 psia formerly, it can control the pneumatic valve (23) automatically or manually. The temperature of the system is obtained by the thermocouple inside the cell (figure 3), it is shown digitally on the controller (16) with a resolution of $0.1^{\circ} \mathrm{C}$. The level of the liquid can be directly read from the level gage (6).

Exiting from the VLE cell, the vapor phase enters the tube side of the vapor line heat exchanger (11),cool water flow continuously through the shell side of the heat exchanger. The vapor phase then condenses and is cooled down close to the ambient temperature in the heat exchanger, and it can be sampled in liquid form through the vapor sampling tank (13). The liquid phase from the cell, passing through the liquid line heat exchanger, can be sampled by the liquid sample tank (14). The rest of the vapor phase and the liquid phase pass the check valves v6 and v7 respectively, then mix together and flow back to the feed tank ready for the next circulation.

\section{Feed composition manipulating:}

For the sake of saving quinoline, The whole Ethylbenzene-Quinoline VLE measurement was started from the low ethylbenzene concentration end, which means that the composition of ethylbenzene in the feed mixture is low at first. After getting all the data points of this composition for all temperature levels, some of the mixture was drained out and about the same volume of fresh ethylbenzene was added to the feed tank to get another composition. Because quinoline is unstable under high temperature, great caution was taken in the analysis. Once the system were found contaminated, the whole system would be drained out thoroughly and fresh feed mixture would take over. During 
the whole experiment process, the whole system had been completely changed three times.

To drain out the mixture out of the system, high pressure $\mathrm{N}_{2}$ (300 psia) is applied to the system, by depressurizing the system through the drain ports (18 and 19), desired amount of liquid can be drained out. The fresh liquid can be added to the feed tank by feed funnel (22).

\section{Operation tips:}

Every time before a new composition starts, the system is filled with $\mathrm{N}_{2}$, to get the accurate measurement, we have to drive all the inert gas out of the VLE cell. First, with the pump working, heat the cell to a temperature at least above the boiling point of one component, with the vapor line control valve fully opening, manipulate the liquid line control valve to make the liquid level in the cell reach the top of the cell, the inert gas in the cell can be driven out through vapor line; to drive out the inert gas in the level gage, gradually open the valve above the gage (v5), it can be observed that the liquid from the cell occupies the empty space pretty soon. After the liquid reach the top of the gage, close the valve, adjust the liquid control valve let the liquid drop to the desired level .

The criteria to judge whether the system in the VLE cell reaches equilibrium or not is that all the three parameters-- temperature, pressure and liquid level in the cell are steady and this steady state should have been kept at least one hour. Normally, in the steady state, the pressure fluctuate \pm 0.5 psia , the temperature will be within $\pm 0.1^{\circ} \mathrm{C}$ range, the liquid level will be within \pm 0.1 ". To push the system to reach the steady state, it involves some empirical skills and a lot of patience. In different conditions, the main oven controller need to be tuned to get the best combination of all parameters (gain, reset time and etc). Because the ethylbenzene-quinoline system is not a quite non ideal system, the equilibrium pressure can always been "guessed" by the Roualt's law, one can always set the pressure on the vapor line controller (7) close to the guessed value and let the controller to control the pneumatic valve automatically, or directly set the output of the controller manually, then by adjusting the output to push the pressure to be close to 
the guessed value. The latter method was frequently used in the experiment, because it is a lot easier to get the steady pressure. To get the constant liquid level is quite tricky, because we can only adjust the liquid line controller (8) manually. In the operation, the flow rate of the pump was set constant, when the temperature of the cell is close to the equilibrium temperature, set the output of the controller a certain value, if the liquid level drops over a period of time, set an another value let the level rise, one can always adjust the output within these bottom and top values to make the range narrow and narrow till the steady level is acquired.

After the temperature, the pressure and the liquid level are all constant, let this state keep at least one hour, then begin to gather the first sample. After every 20-30 minute, collect the other sample. For one data point, five or six samples of liquid and vapor phase each were collected in this experiment.

Every time before the sampling, the sample bottle need to be washed, the liquid from the system used to wash the bottles was collected and returned to the system through the feed funnel. Because of the small size of the sample $(1-2 \mathrm{ml})$, for the same feed composition, there is no necessity to compensate the feed during the experiment.

\section{METHOD OF ANALYSIS:}

To analyze the vapor and liquid samples from the VLE apparatus a Liquid Chromatograph (LC) was employed. The equipment used for the data analysis is:

$\begin{array}{ll}\text { Instrument: } & \text { Perkin- Elmer LC410 pump } \\ \text { Injector: } & \text { Rheodyne Model } 7125 \text { Sample Injection Valve } \\ \text { Detector: } & \text { Perkin-Elmer UV spectrophotometric detector } \\ & \text { kept at } 254 \mathrm{~nm} \\ \text { Column: } & \text { Perkin-Elmer } 3 \mathrm{cmX} 3 \mathrm{~cm} \mathrm{C-18} \mathrm{column} \\ \text { Mobile phase : } & 70 \% \text { methanol, } 30 \% \text { water }\end{array}$


Flow rate: $\quad 1.8 \mathrm{ml} / \mathrm{min}$

Sample concentration: 5 microliter of sample dissolved into $1 \mathrm{ml}$ of methanol

Sample size : $\quad 3$ microliter

Operation pressure : $\quad$ 1900-2200 psia (depend on different columns)

Data analysis : $\quad$ Software Perkin-Elmer Turbochrom 4, Rev 4.1

The standard solutions used for calibration were made by weighting. The balance used for this purpose has a resolution of $0.0001 \mathrm{~g}$. Nine standard solutions over the whole range (ethylbenzene 0-100\%) were made according to the ethylbenzene mole concentration. By running the sample which had a certain mole ratio of ethylbenzene and quinoline, we got an corresponding area ratio of their peaks, we express this as:

$$
\frac{M e}{M q}=K \frac{A e}{A q}
$$

In the above equation, $\mathrm{Me}$ is the mole amount of ethylbenzene, $\mathrm{Mq}$ is the mole amount of quinoline, Ae is the peak area of the ethylbenzene, Aq is the peak area of quinoline, $\mathrm{K}$ is the conversion factor. If we plot $\mathrm{Ae} / \mathrm{Aq}$ versus $\mathrm{Me} / \mathrm{Mq}$ for all the nine compositions, it can be noticed that all the points are basically on the same line and the slope is $\mathrm{K}$. by running the calibrations runs we get the $\mathrm{K}$ value which is 11.585 . We can calculate the ethylbenzene mole concentration of the samples, Ce, according to the following equation

$$
\mathrm{Ce}=\frac{M e}{M e+M q}=\frac{K A e}{K A e+A q}=\frac{K \frac{A e}{A q}}{1+K \frac{A e}{A q}}
$$

During the actual analysis, every sample ran at least twice, the final area ratio was the average of all the individual runs, the overall error of this method is about $2 \%$. 


\section{EXPERIMENTAL RESULTS:}

The criteria to judge if the system is at equilibrium status or not is that the temperature, pressure and the liquid level are all constant. Typically, to generate one data point, 7-9 hours is needed to reach this stage, sometimes it may take more than 12 hours or it might never reach the equilibrium state if no appropriate adjustments are carried out. Continuous physical attendance is required all the time during the experiment. One reason is that sometimes if the vapor and liquid control valves are adjusted such that the chemical out of the equilibrium cell is less than that enters the cell, the liquid is going to accumulate in the cell. As the pump keep on working, the whole system might be destroyed by the high pressure generated by the pump. On the other hand, if the chemicals leave the cell are less than the chemicals enter the cell, finally, there will be no liquid left in the cell, not to say the equilibrium. In the process push the system to reach the equilibrium state, though empirical skills might be a big help, extreme patience is the critical to get successful measurements.

In this work, the ethylbenzene-quinoline system is studied. Seven isotherms are generated, they are $225^{\circ} \mathrm{C}, 250^{\circ} \mathrm{C}, 280^{\circ} \mathrm{C}, 310^{\circ} \mathrm{C}, 340^{\circ} \mathrm{C}, 365^{\circ} \mathrm{C}, 380^{\circ} \mathrm{C}$. The chemicals are all bought from Aldrich company, quinoline has a purity of over $98 \%$, and the purity of the ethylbenzene is above $99.8 \%$. Because quinoline is very easy to get contaminated at high temperature, great caution was taken during the whole measurement, once the quinoline was found contaminated, all the chemicals in the system were drained out, fresh chemicals were refilled to the system to continue the runs.

The raw data were massaged by keeping $\mathrm{T}$ and $\mathrm{X}$ fixed and varying $\mathrm{P}$ and $\mathrm{Y}$ in a very narrow range around the experimentally measured values, so that a smooth representation of data is obtained over the entire isotherm. This is necessary if the data are expected to satisfy the thermodynamic consistency tests. Variations of $\mathrm{Y}$ and $\mathrm{P}$ within the range of possible experimental errors ( $\pm 3 \%$ for $\mathrm{Y}$ and $\pm 1 \%$ for $\mathrm{P}$ ) can cause a large effect on the results of the integrated or the point-by-point thermodynamic consistency tests. Data massaging of this type is quite time-consuming, and was performed for all the data, but especially for the $310 \mathrm{C}$ and $340 \mathrm{C}$ isotherms, for which 
data were measured over the entire range of concentrations. For the vapor pressure of pure ethylbenzene ${ }^{(4)}$ and pure quinoline ${ }^{(5)}$ we all adopted the literature data.

In the following text, Table 1 to table 7 list the PTxy data on every isotherms mentioned above, Figures 4,6,8,10,12,14 and 16 give the corresponding $x-y$ diagrams respectively for all the isotherms. Figures 5,7,9,11,13,15 and 17 give the corresponding $\mathrm{P}$-xy diagrams respectively for all the isotherms

For the typical apparatus we are using, if the pressure of the system are too low, the experiment can not be operated, because there is no enough pressure to push the liquid to flow. For this reason, on the $225^{\circ} \mathrm{C}$ isotherm, only four points on the ethylbenzene rich end were measured.

Table 1. VLE data at $225^{\circ} \mathrm{C}$

\begin{tabular}{|l|l|l|l|}
\hline Temperature $\mathrm{K}$ & Pressure Pa & $\mathrm{X}_{\text {ethylbenzne }}(\mathrm{mol} \%)$ & $\mathrm{Y}_{\text {ethylbenzene }}(\mathrm{mol} \%)$ \\
\hline 498.25 & 394721.6 & 43.591 & 98.002 \\
\hline 498.15 & 489000.0 & 60.056 & 98.805 \\
\hline 498.25 & 575514.4 & 77.448 & 99.302 \\
\hline 498.15 & 660510.1 & 93.955 & 99.611 \\
\hline 498.15 & 682250.0 & 100.0 & 100.0 \\
\hline
\end{tabular}




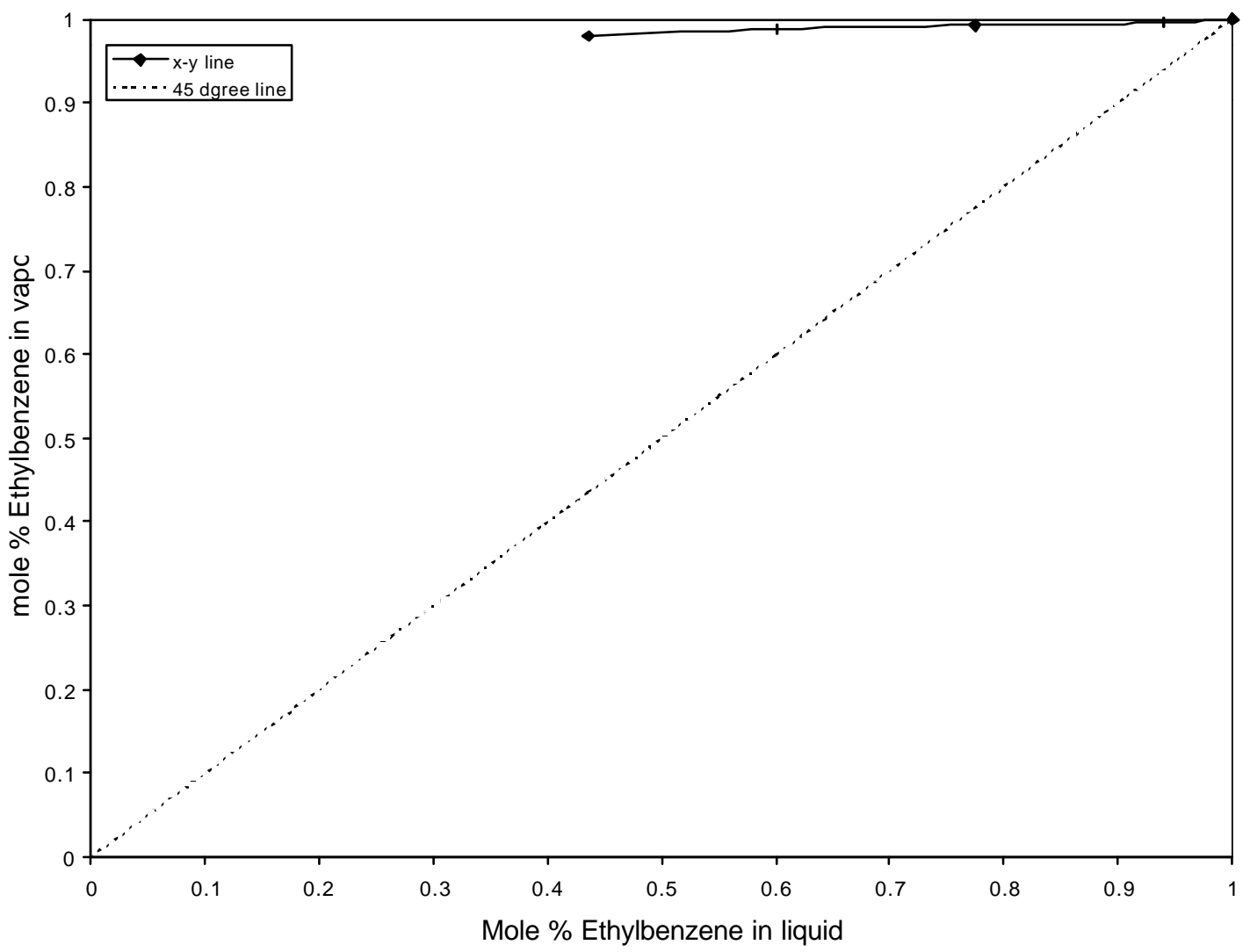

Figure 4. Ethylbenzene-Quinoline Isotherm at $225^{\circ} \mathrm{C}$ 


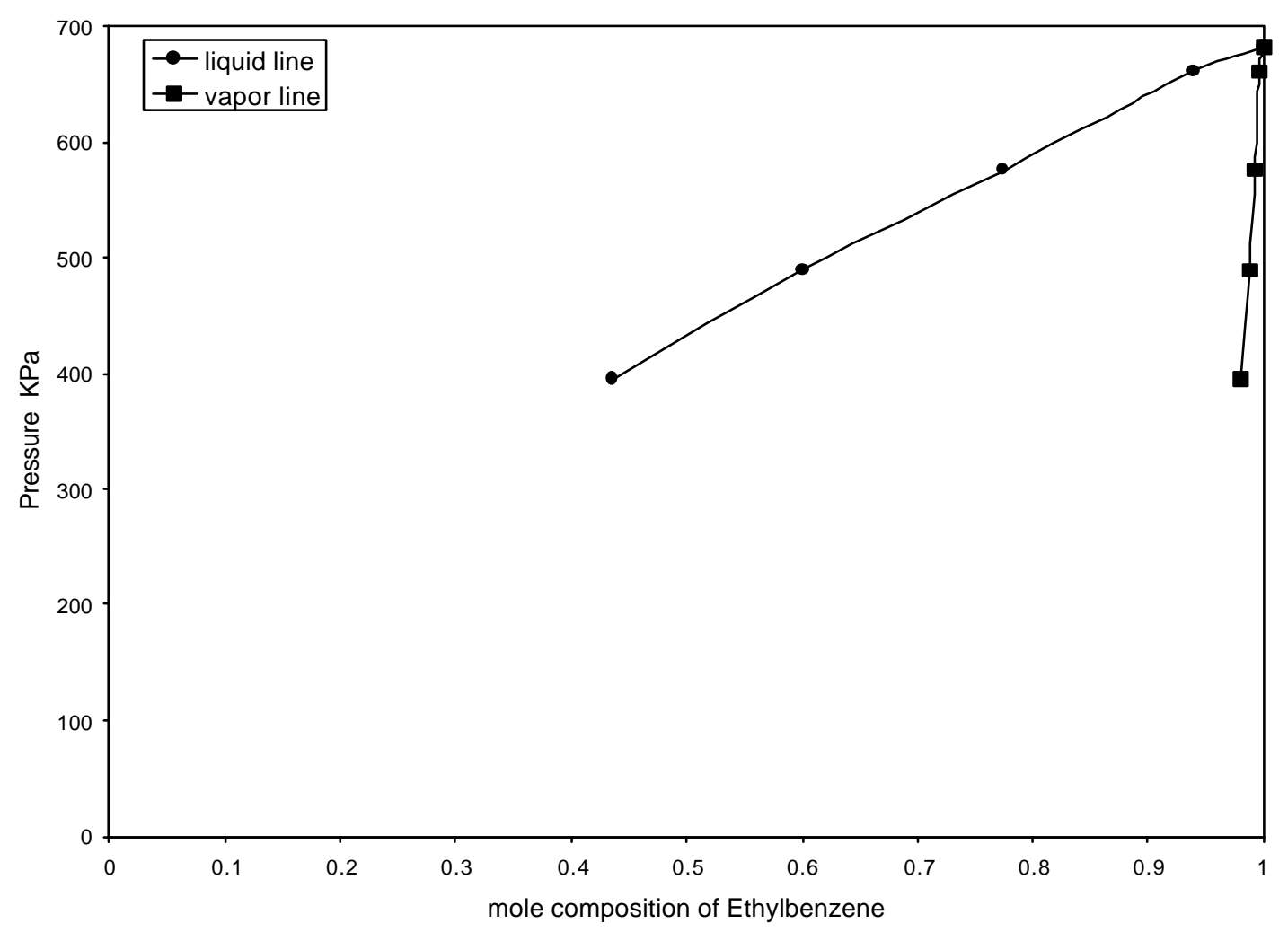

Figure 5. Ethylbenzene-Quinoline $\mathrm{P}-\mathrm{xy}$ diagram at $225^{\circ} \mathrm{C}$

Table 2. Ethylbenzene-Quinoline VLE data at $250^{\circ} \mathrm{C}$

\begin{tabular}{|l|l|l|l|}
\hline Temperature K & Pressure Pa & $X_{\text {etthylbenzene }}(\mathrm{mol} \%)$ & Yethylbenzene $(\mathrm{mol} \%)$ \\
\hline 523.15 & 134875.0 & 0.0 & 0.0 \\
\hline 523.15 & 192005.0 & 4.42 & 82.868 \\
\hline 523.15 & 436003.2 & 29.996 & 95.303 \\
\hline 523.15 & 591723.8 & 45.002 & 96.837 \\
\hline 523.25 & 722013.0 & 59.403 & 97.100 \\
\hline 523.25 & 852805.5 & 77.349 & 97.400 \\
\hline 523.25 & 983091.9 & 94.235 & 98.500 \\
\hline 523.15 & 1025400.0 & 100.0 & 100.0 \\
\hline
\end{tabular}




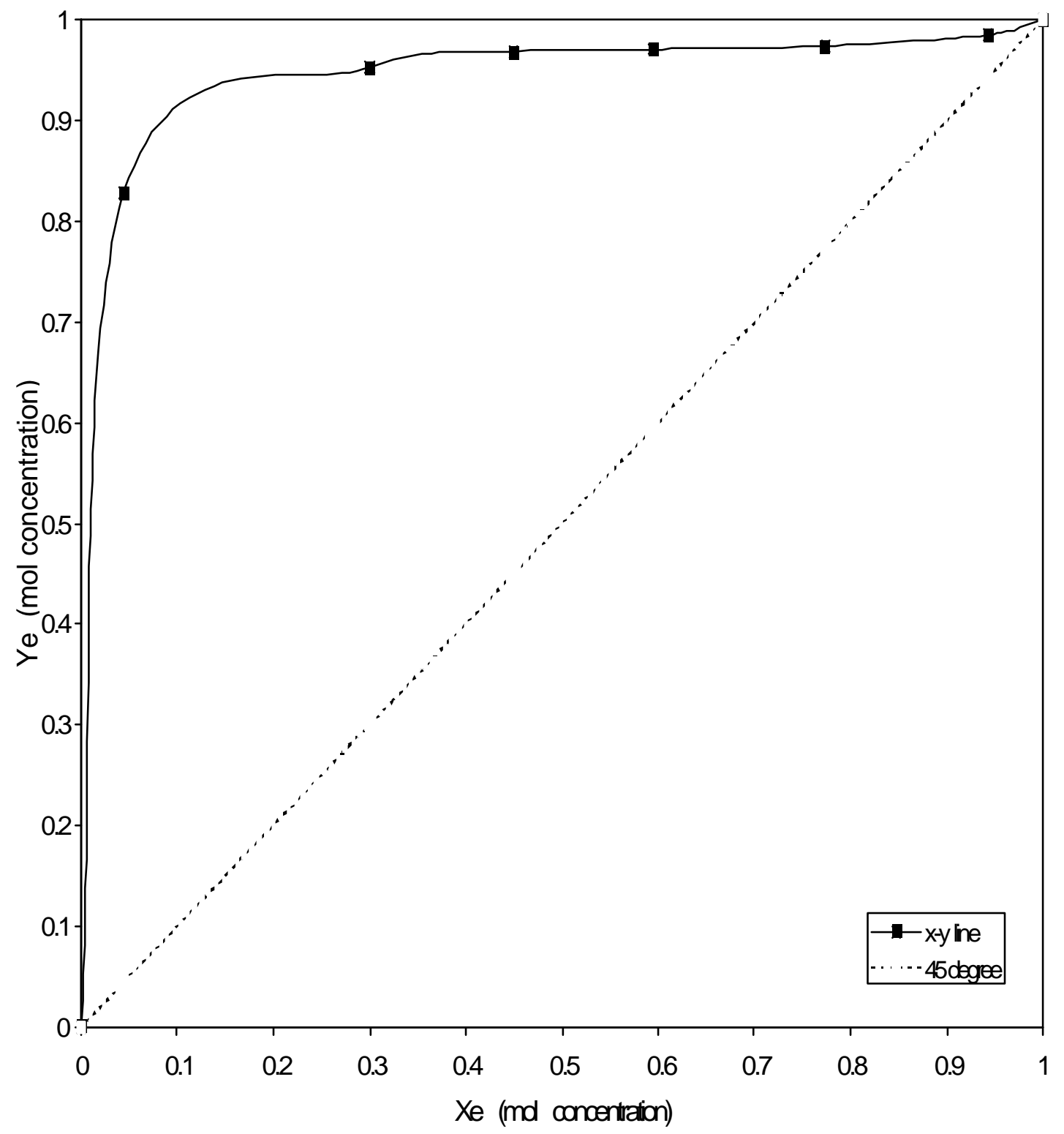

Figure 6. Ethylbenzene-Quinoline Isotherm at $250{ }^{\circ} \mathrm{C}$ 


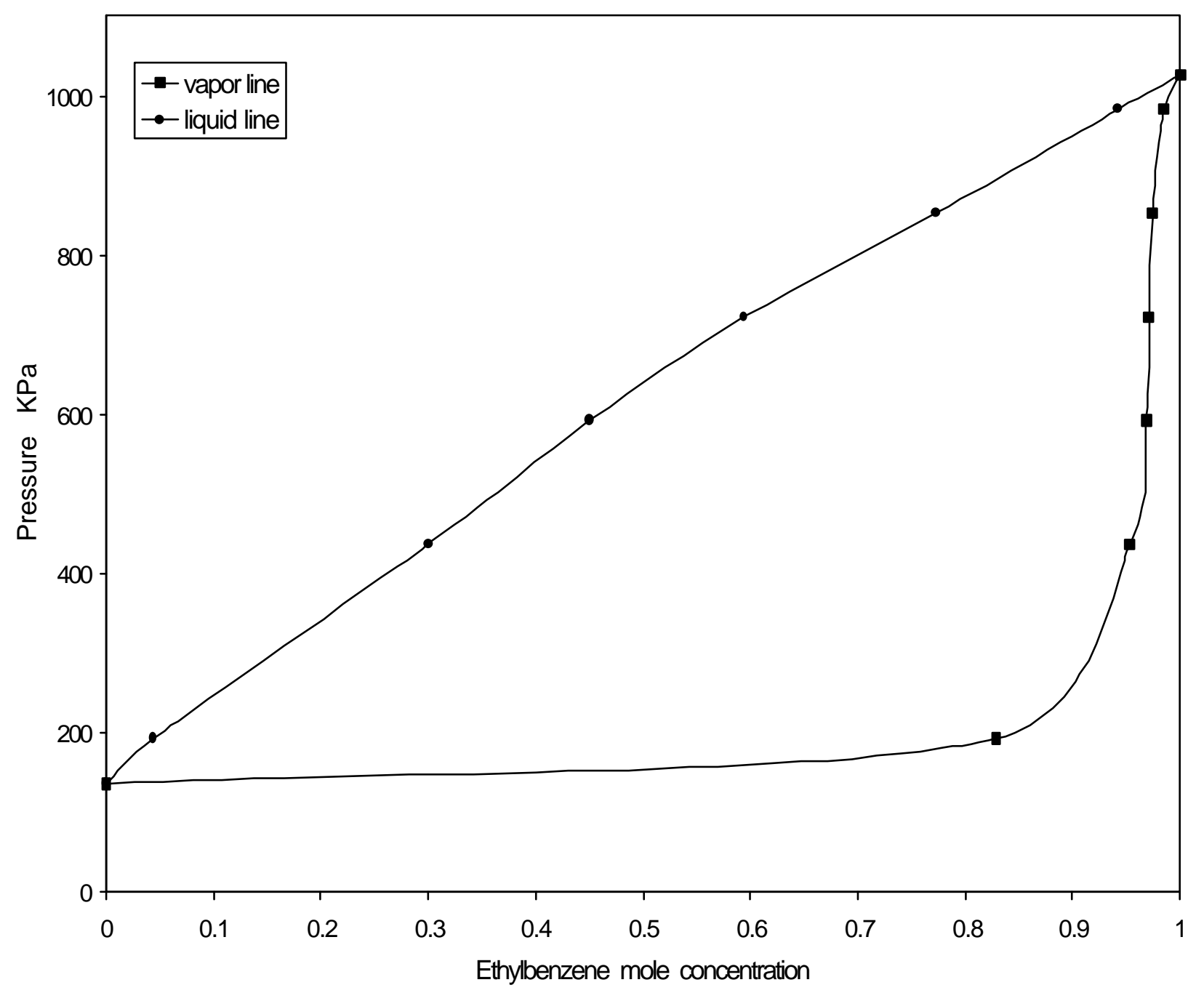

Figure 7. Ethylbenzene-Quinoline $\mathrm{P}-\mathrm{xy}$ diagram at $250^{\circ} \mathrm{C}$

Table 3. Ethylbenzene-Quinoline VLE data at $280{ }^{\circ} \mathrm{C}$

\begin{tabular}{|l|l|l|l|}
\hline Temperature K & Pressure Pa & $\mathrm{X}_{\text {ethylbenzene }} \quad(\mathrm{mol} \%)$ & $\mathrm{Y}_{\text {ethylbenzene }}(\mathrm{mol} \%)$ \\
\hline 553.15 & 243200.0 & 0.0 & 0.0 \\
\hline 553.55 & 311302.6 & 2.18 & 26.362 \\
\hline 553.55 & 484080.0 & 14.694 & 78.996 \\
\hline
\end{tabular}


Table 3. Ethylbenzene-Quinoline VLE data at $280{ }^{\circ} \mathrm{C}$ (continued)

\begin{tabular}{|l|l|l|l|}
\hline 553.55 & 673600.0 & 28.750 & 85.800 \\
\hline 553.05 & 925620.0 & 47.699 & 89.453 \\
\hline 553.25 & 1120000.0 & 61.500 & 91.700 \\
\hline 553.25 & 1314799.0 & 77.500 & 94.752 \\
\hline 553.25 & 1560409.0 & 93.603 & 98.050 \\
\hline 553.15 & 1695000.0 & 100.0 & 100.0 \\
\hline
\end{tabular}

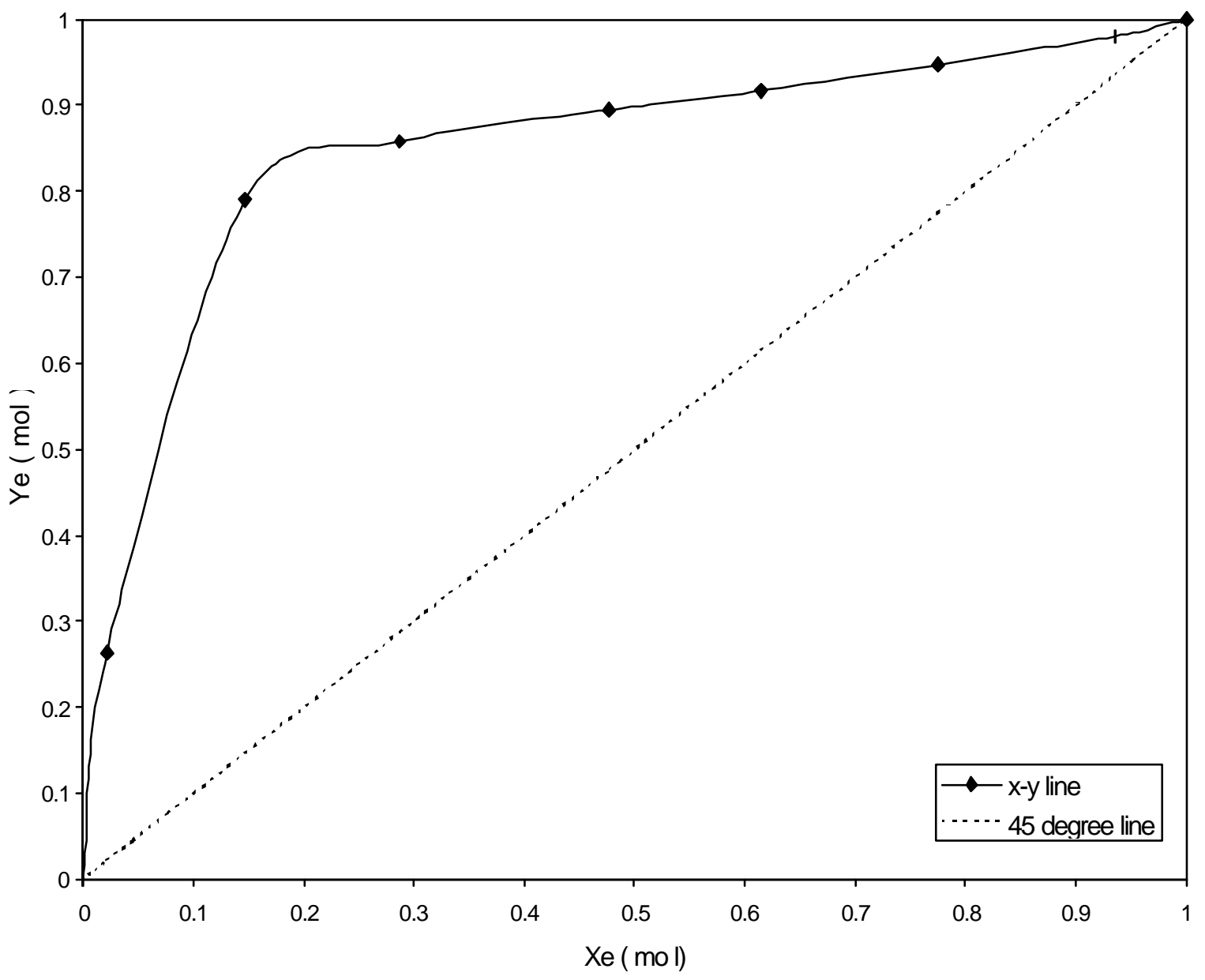

Figure 8. Ethylbenzene-Quinoline Isotherm at $280^{\circ} \mathrm{C}$ 


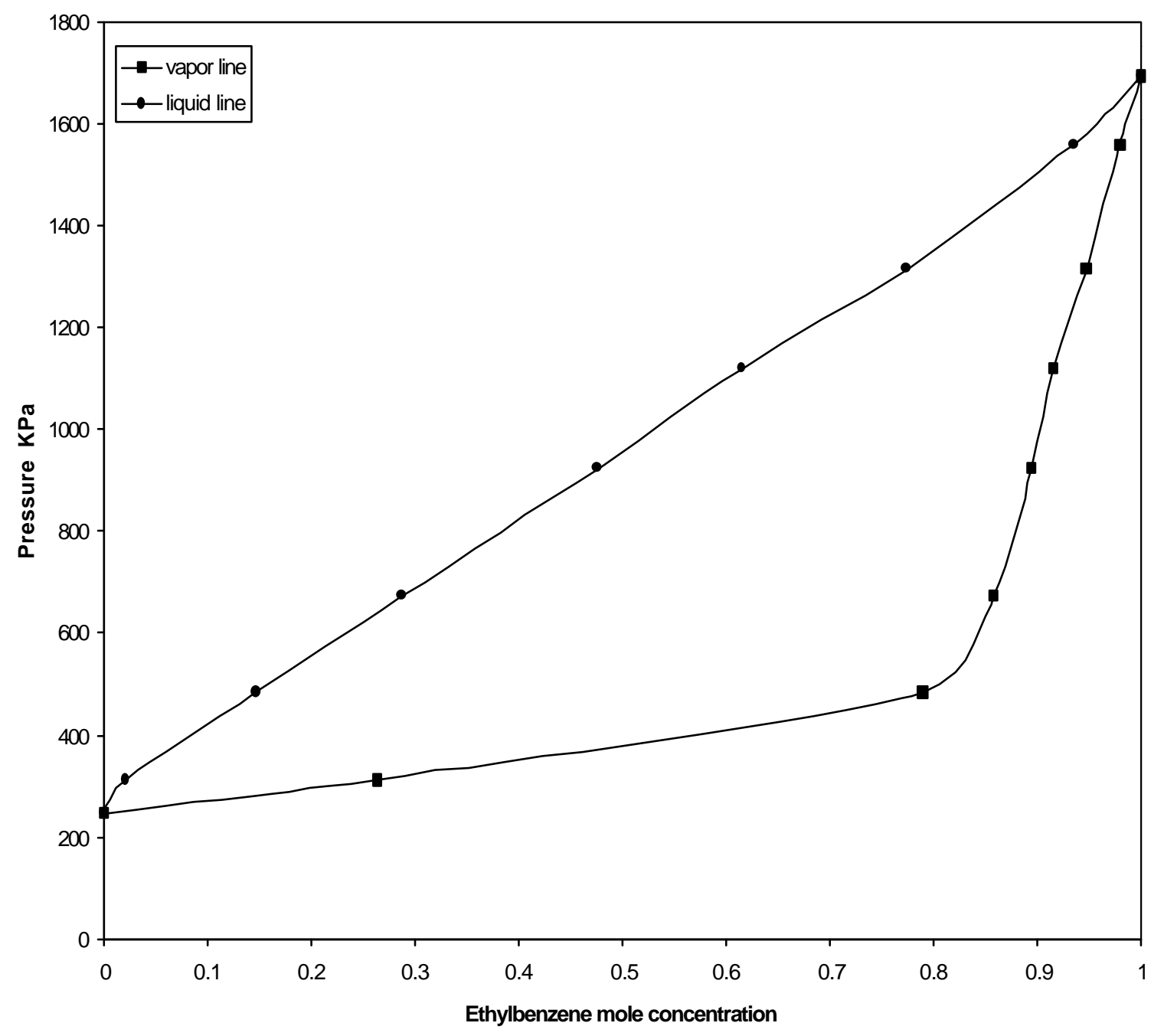

Figure 9. Ethylbenzene-Quinoline P-xy diagram at $280^{\circ} \mathrm{C}$

Table 4. Ethylbenzene-Quinoline VLE data at $310^{\circ} \mathrm{C}$

\begin{tabular}{|l|l|l|l|}
\hline Temperature K & Pressure Pa & $X_{\text {ethylbenzene } \quad(m o l \%)}$ & Yethylbenzene (mol\%) \\
\hline 583.15 & 412750.0 & 0.0 & 0.0 \\
\hline 583.25 & 489005.6 & 19.19 & 15.236 \\
\hline 583.15 & 839763.0 & 17.073 & 54.483 \\
\hline
\end{tabular}


Table 4. Ethylbenzene-Quinoline VLE data at $310^{\circ} \mathrm{C}$ (continued)

\begin{tabular}{|l|l|l|l|}
\hline 583.15 & 1085360.0 & 30.285 & 67.634 \\
\hline 583.55 & 1307506.0 & 42.839 & 75.299 \\
\hline 583.25 & 1648495.0 & 61.532 & 82.759 \\
\hline 583.35 & 1964306.0 & 78.233 & 89.070 \\
\hline 583.15 & 2301589.0 & 95.354 & 97.044 \\
\hline 583.15 & 2394782.0 & 100.0 & 100.0 \\
\hline
\end{tabular}

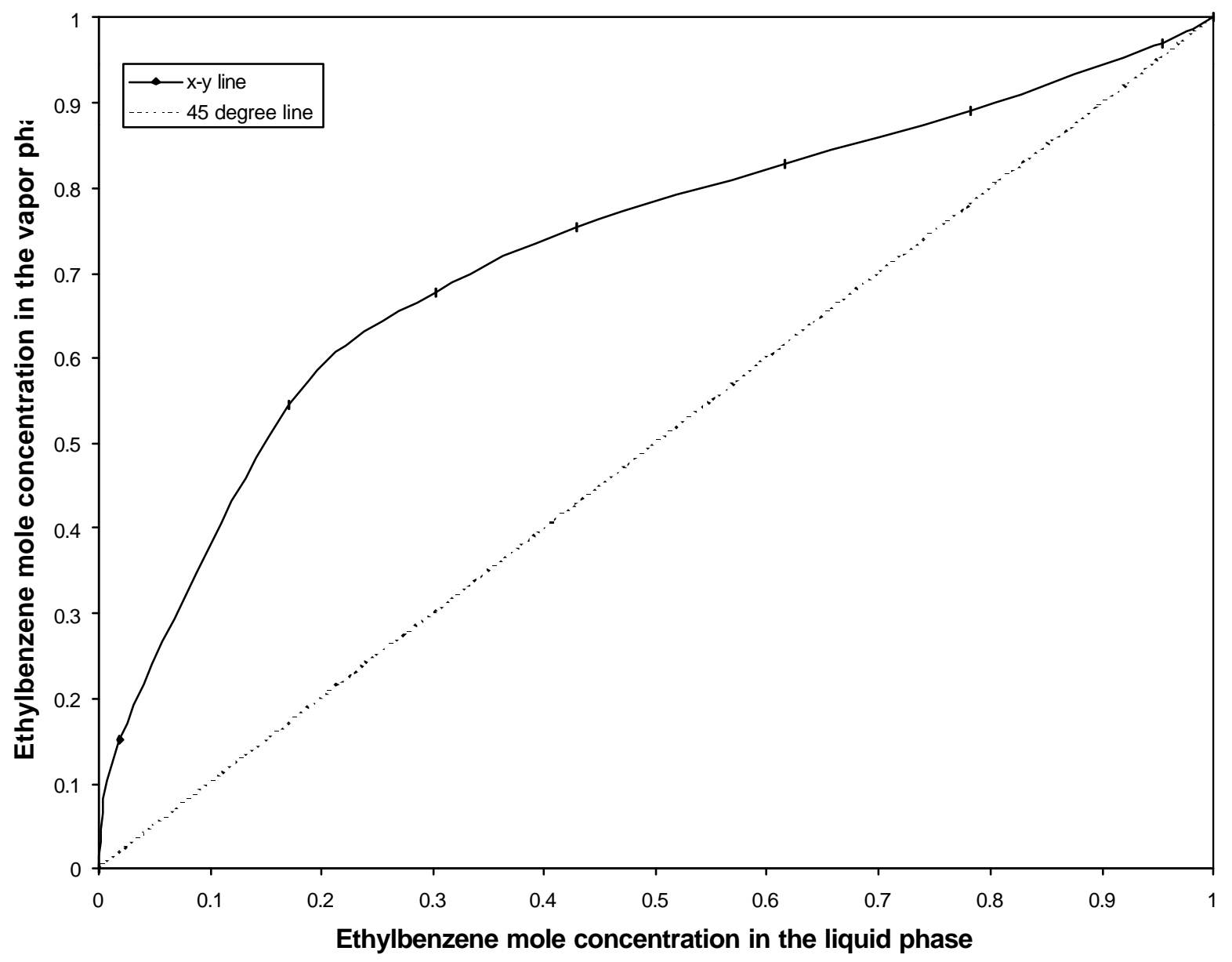

Figure 10. Ethylbenzene-Quinoline Isotherm at $310^{\circ} \mathrm{C}$ 


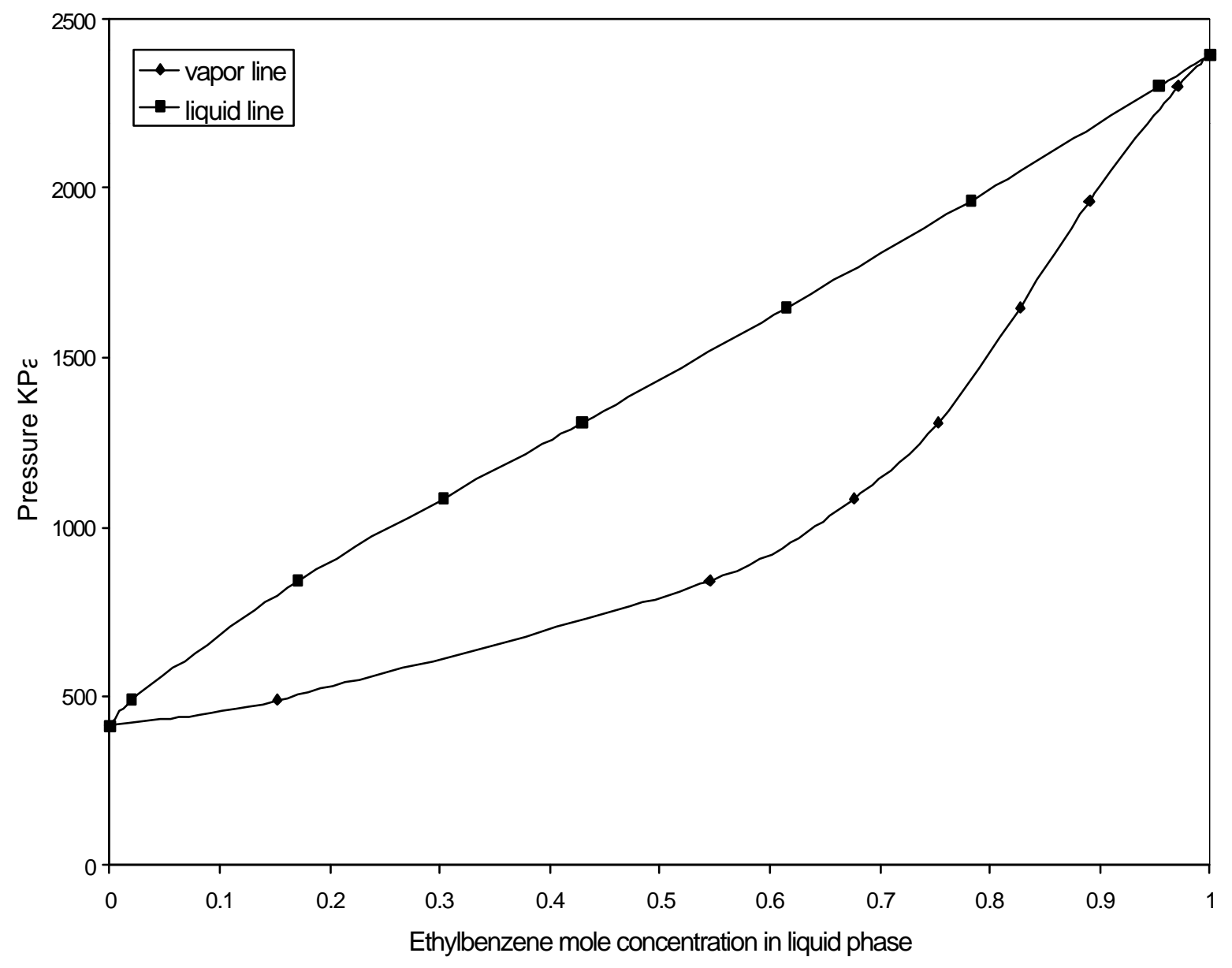

Figure 11. Ethylbenzene-Quinoline P-xy diagram at $310^{\circ} \mathrm{C}$

Table 5. Ethylbenzene-Quinoline VLE data at $340^{\circ} \mathrm{C}$

\begin{tabular}{|l|l|l|l|}
\hline Temperature K & Pressure Pa & $X_{\text {ethylbenzene }}$ & $Y_{\text {ethylbenzene }}$ \\
\hline 613.15 & 655900.0 & 0.0 & 0.0 \\
\hline 613.25 & 788122.4 & 3.402 & 17.856 \\
\hline 613.15 & 1166550.0 & 17.564 & 48.282 \\
\hline 613.25 & 1403450.0 & 27.744 & 59.584 \\
\hline
\end{tabular}


Table 5. Ethylbenzene-Quinoline VLE data at $340^{\circ} \mathrm{C}$ (continued)

\begin{tabular}{|l|l|l|l|}
\hline 613.15 & 1793009.0 & 44.000 & 71.375 \\
\hline 613.25 & 2280410.0 & 62.257 & 80.226 \\
\hline 613.15 & 2709882.0 & 77.582 & 86.800 \\
\hline 613.15 & 3207578.0 & 93.732 & 95.075 \\
\hline 613.15 & 3470751.0 & 100.0 & 100.0 \\
\hline
\end{tabular}

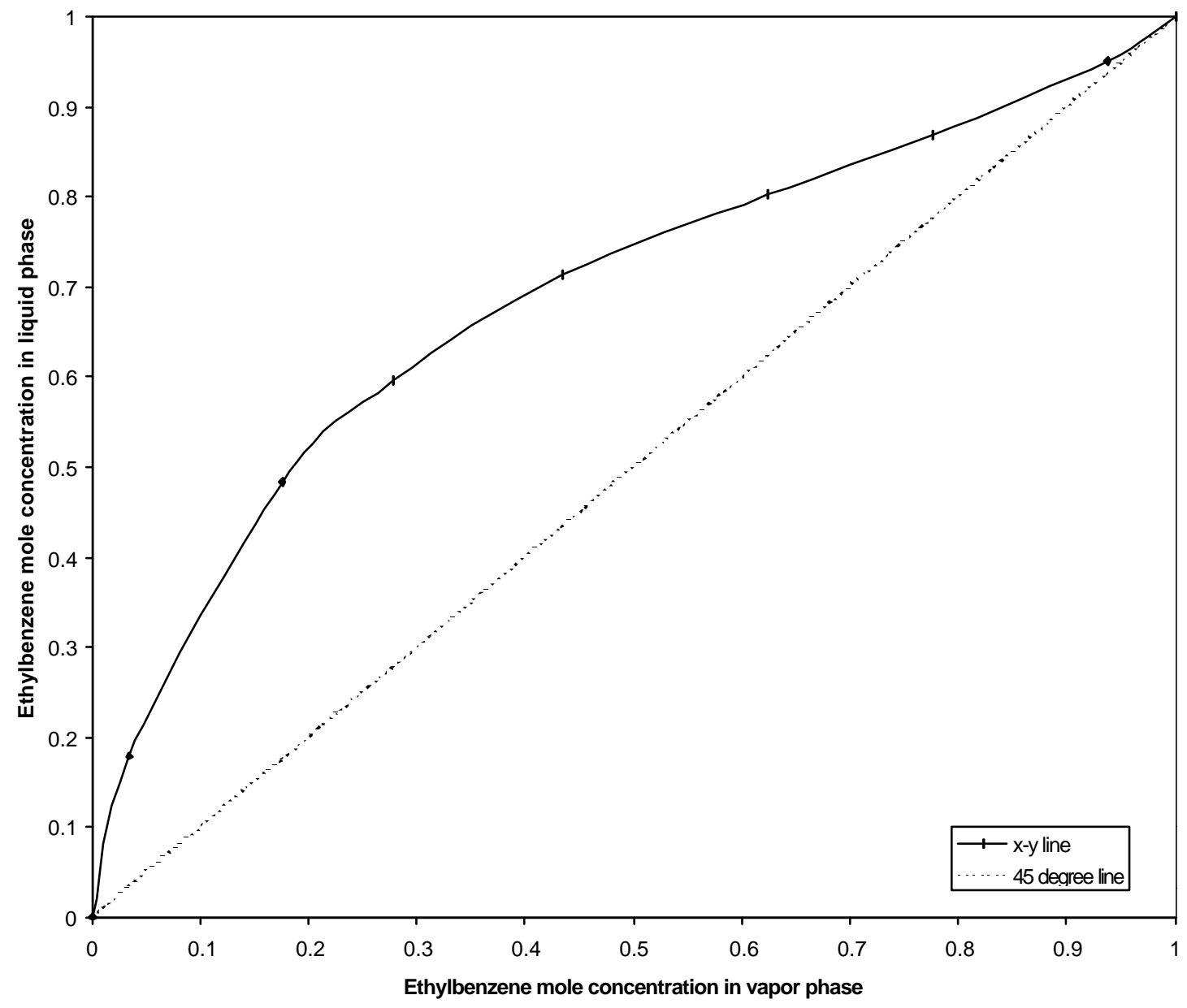

Figure 12. Ethylbenzene-Quinoline isotherm at $340^{\circ} \mathrm{C}$ 


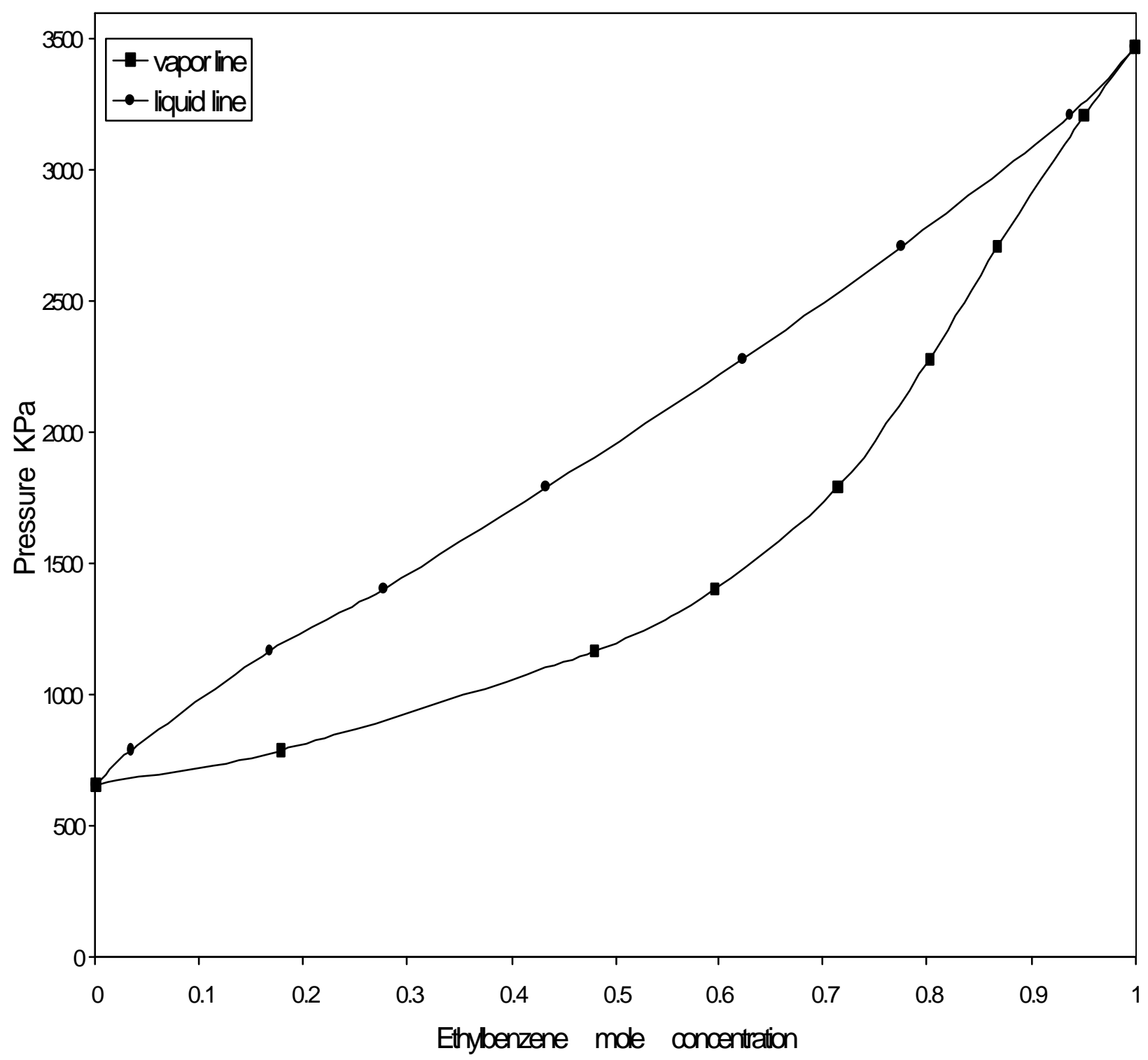

Figure 13. Ethylbenzene-Quinoline P-xy diagram at $340^{\circ} \mathrm{C}$

Table 6. Ethylbenzene-Quinoline VLE data at $365^{\circ} \mathrm{C}$

\begin{tabular}{|l|l|l|l|}
\hline Temperature $\mathrm{K}$ & Pressure Pa & $\mathrm{X}_{\text {ethylbenzene }} \quad(\mathrm{mol} \%)$ & Yethylbenzene $(\mathrm{mol} \%)$ \\
\hline 638.15 & 944000.0 & 0.0 & 0.0 \\
\hline
\end{tabular}


Table 6. Ethylbenzene-Quinoline VLE data at $365^{\circ} \mathrm{C}$ (continued)

\begin{tabular}{|l|l|l|l|}
\hline 638.15 & 1016947.0 & 0.384 & 1.510 \\
\hline 638.25 & 1131282.0 & 2.806 & 13.123 \\
\hline 638.55 & 1506090.0 & 14.892 & 42.164 \\
\hline 638.15 & 1894330.0 & 27.199 & 55.151 \\
\hline 638.15 & 2479886.0 & 42.976 & 67.962 \\
\hline 638.15 & 2796077.0 & 55.485 & 74.219 \\
\hline
\end{tabular}

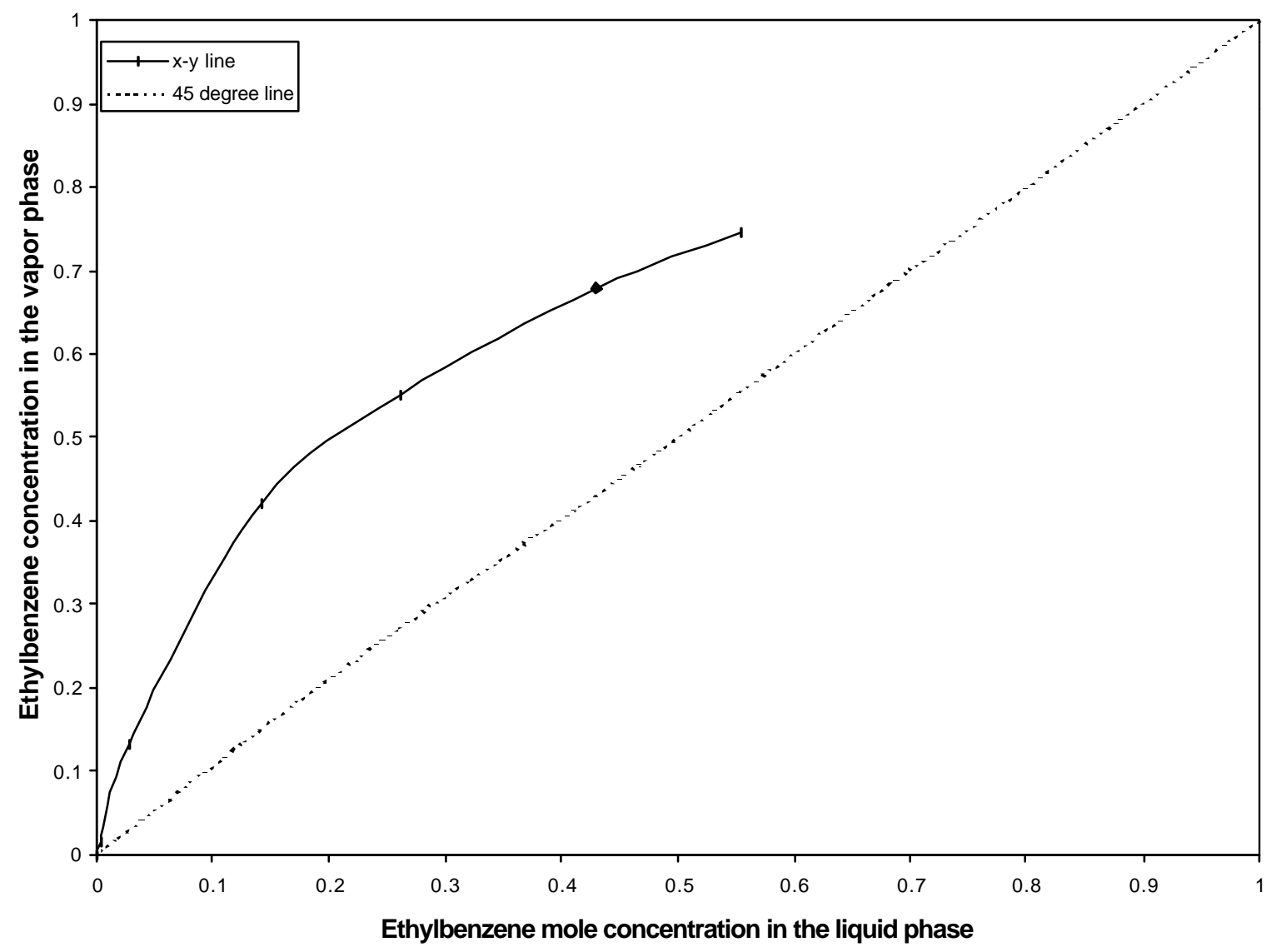

Figure 14. Ethylbenzene-Quinoline Isotherm at $365^{\circ} \mathrm{C}$ 


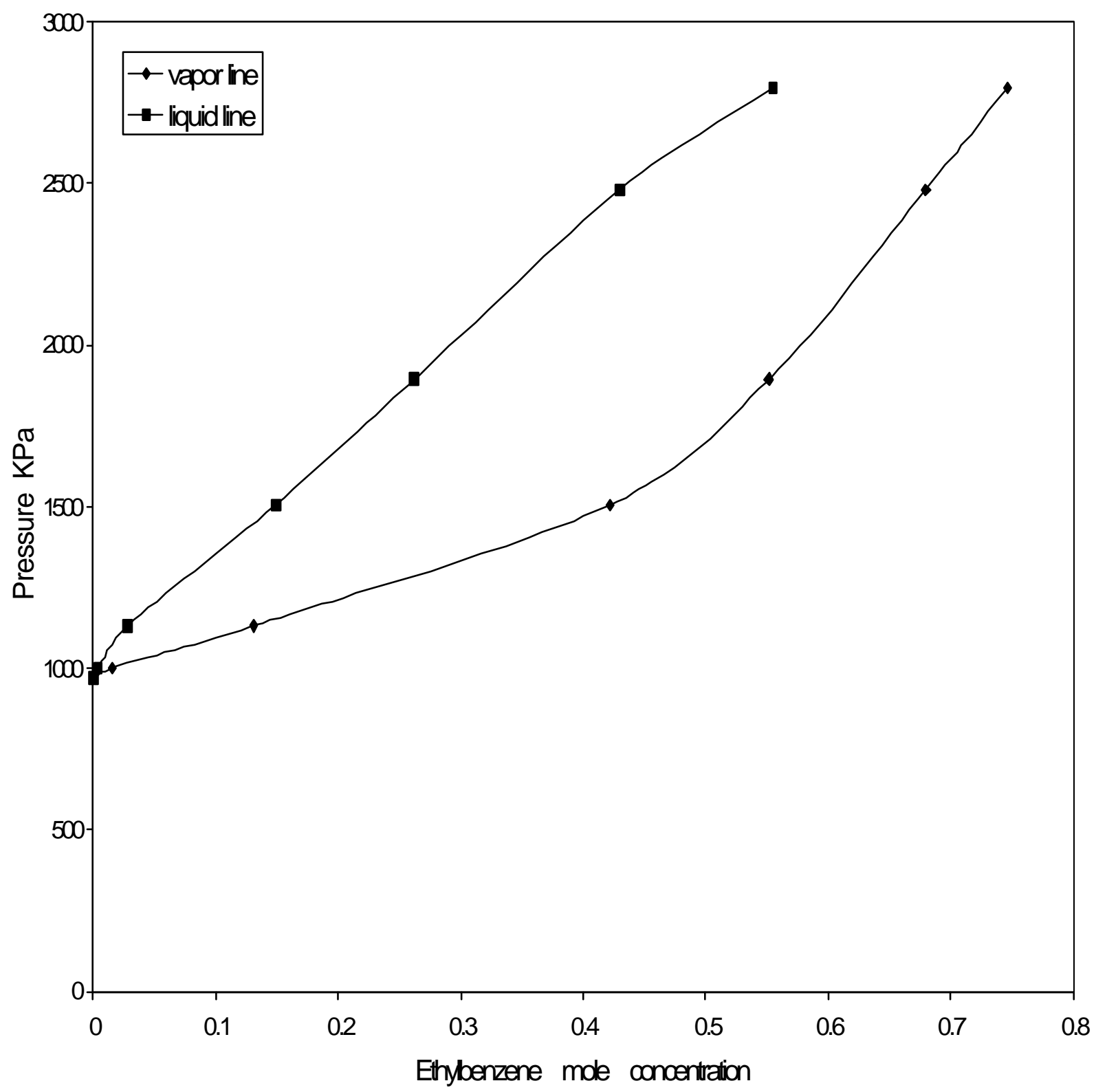

Figure 15. Ethylbenzene-Quinoline P-xy diagram 
Table 7 Ethylbenzene-Quinoline VLE data at $380^{\circ} \mathrm{C}$

\begin{tabular}{|l|l|l|l|}
\hline Temperature K & Pressure Pa & $X_{\text {ethylbenzene }}(\mathrm{mol} \%)$ & $Y_{\text {ethylbenzene }}(\mathrm{mol} \%)$ \\
\hline 653.15 & 1148000 & 0.0 & 0.0 \\
\hline 653.15 & 1224283 & 0.501 & 1.327 \\
\hline 653.15 & 1415206 & 4.189 & 10.046 \\
\hline 653.15 & 1772640 & 15.112 & 37.388 \\
\hline 653.15 & 2269410 & 28.757 & 53.700 \\
\hline 653.15 & 2888604 & 42.778 & 65.956 \\
\hline
\end{tabular}

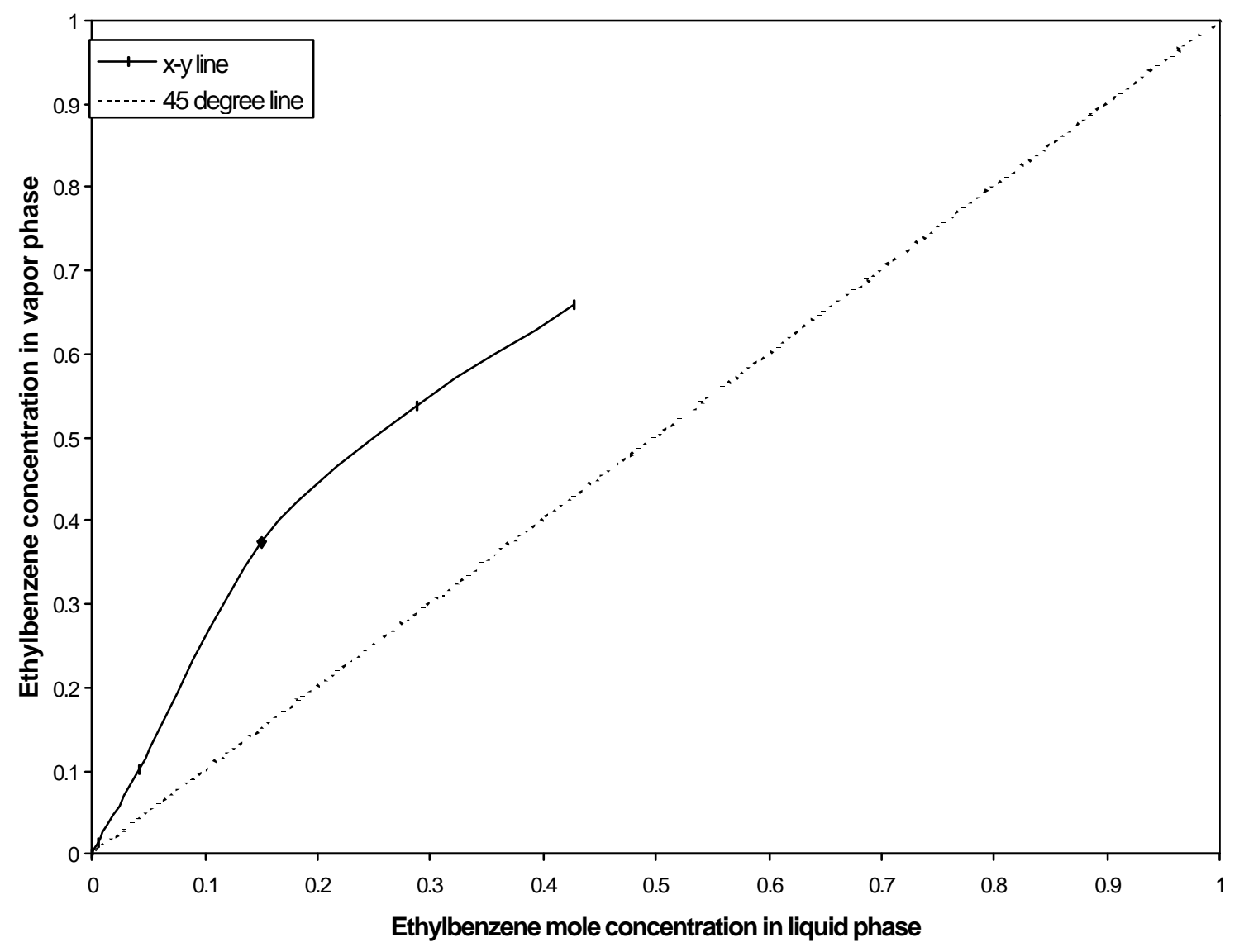

Figure 16. Ethylbenzene-Quinoline Isotherm at $380^{\circ} \mathrm{C}$ 


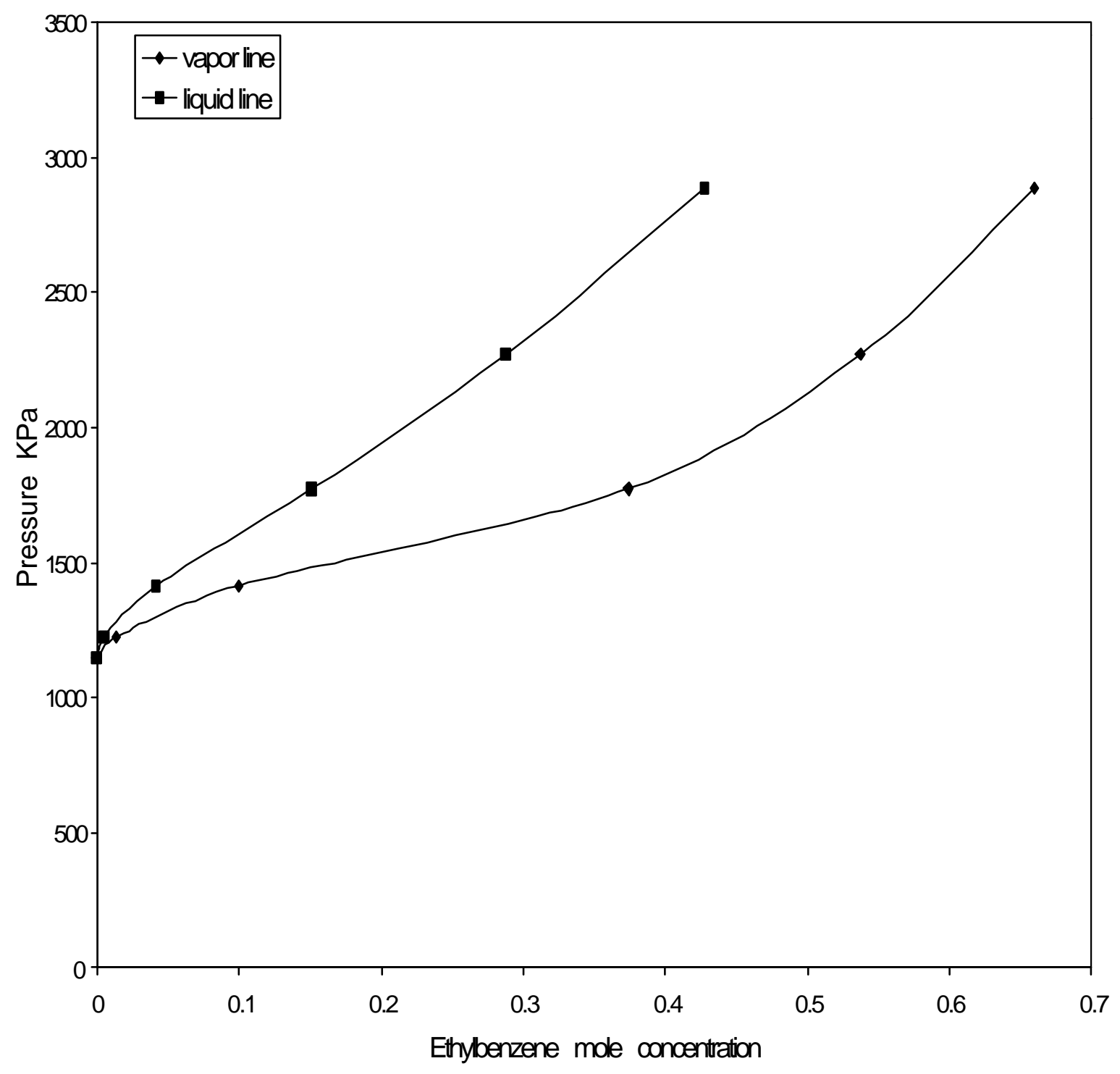

Figure 17. Ethylbenzene-Quinoline P-xy diagram at $380^{\circ} \mathrm{C}$

You might have noticed that we do not measure the full range VLE data at $365^{\circ} \mathrm{C}$ and $380^{\circ} \mathrm{C}$, this is because the critical temperature of ethylbenzene is only $343^{\circ} \mathrm{C}$ though the quinoline's is $427^{\circ} \mathrm{C}$. This feature of the system we worked on determined we cannot get the full range data beyond $343^{\circ} \mathrm{C}$. The data we presented here is the best we can do. 
The experimental results for each isotherm are given in the above part,

Figures 18 and 19 illustrate how they look like if all the isotherms are put together.

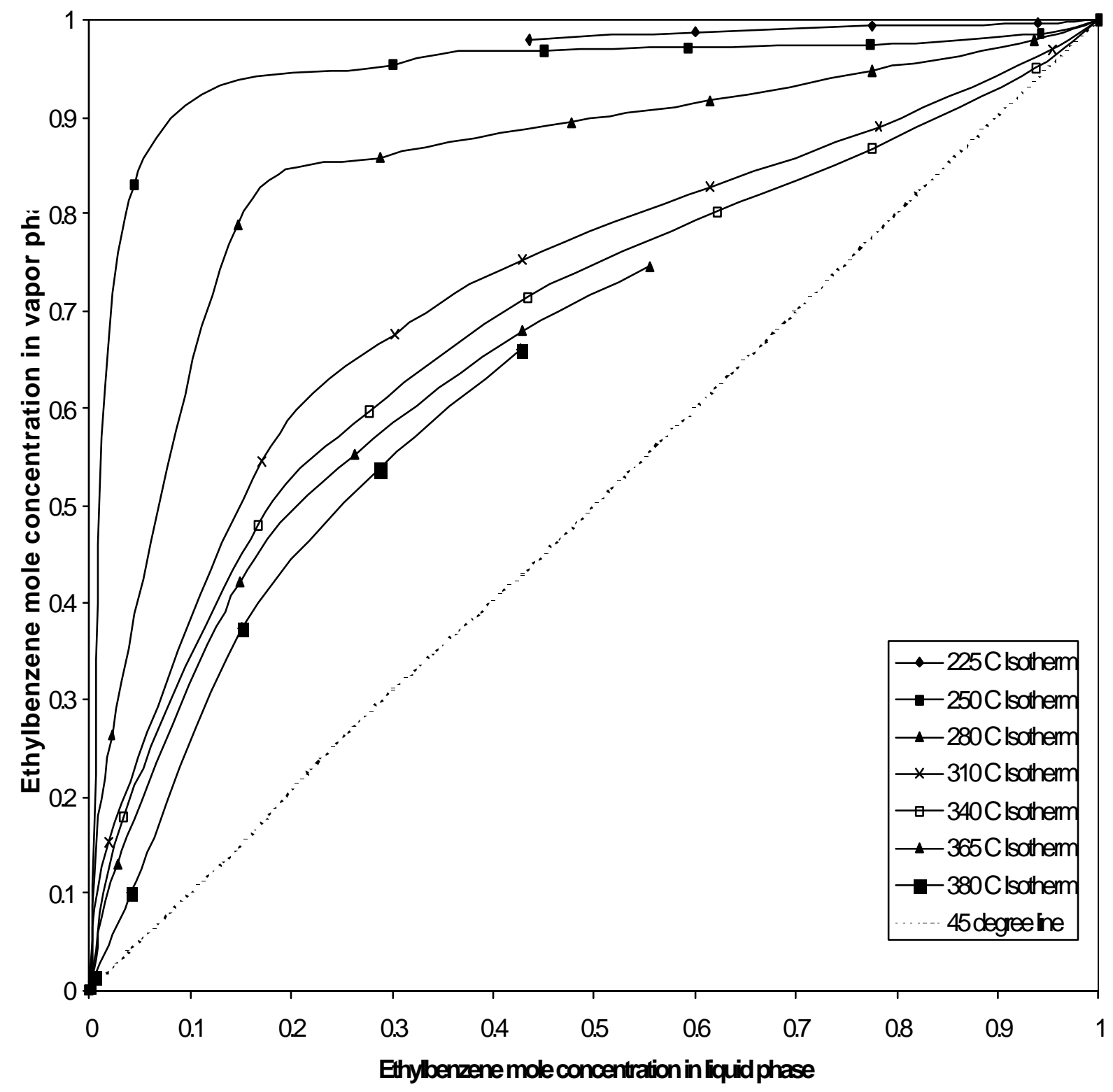

Figure 18. Ethylbenzene-Quinoline x-y diagram for all Isotherms 


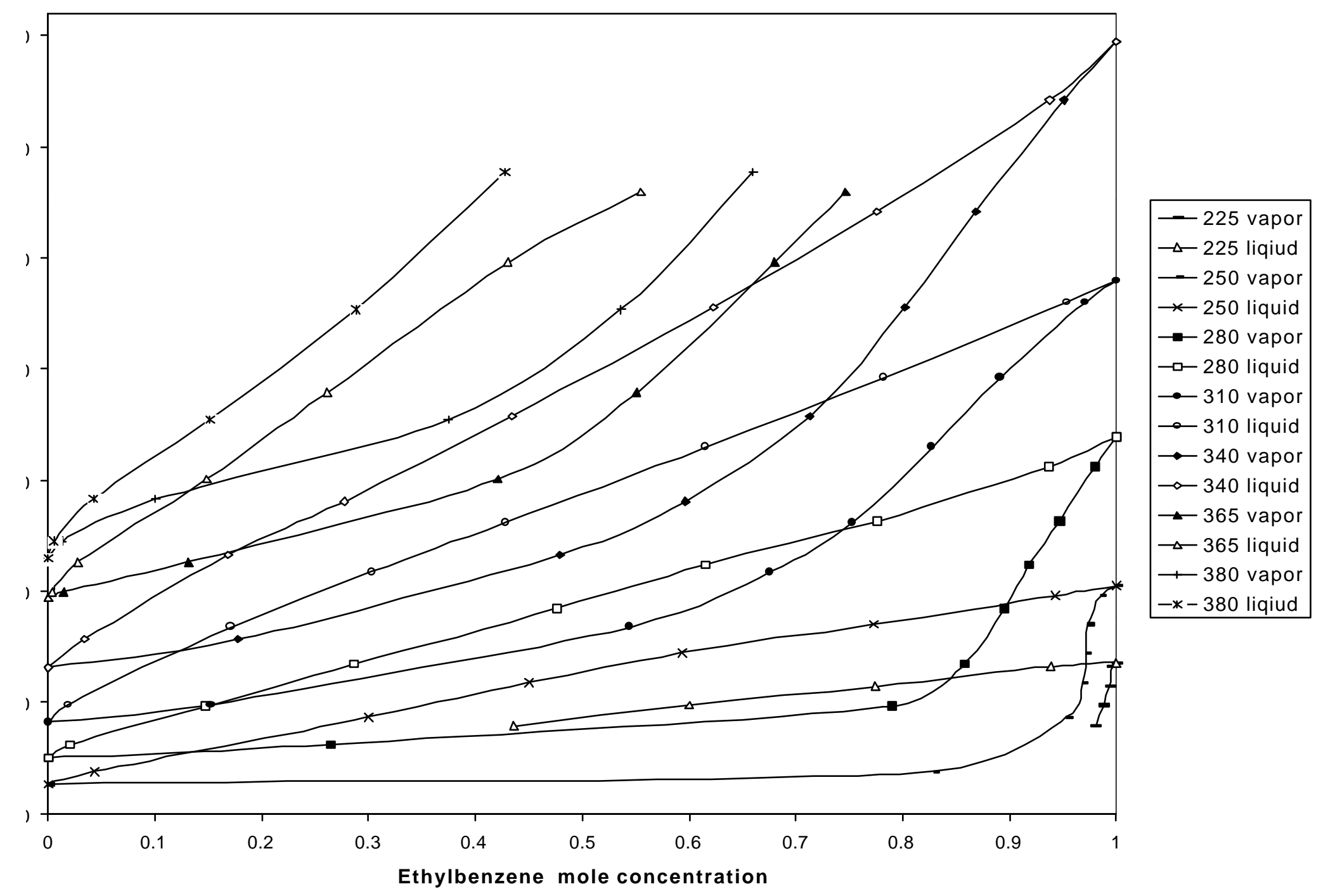

Figure 19 Ethylbenzene-Quinoline P-xy diagram for all the isotherms 


\section{Data smoothing and the thermodynamic consistency test}

The thermodynamic consistency test and data smoothing are normally applied to the raw VLE data. Whether the raw data is satisfied the thermodynamic consistency test or if it can be smoothed within the error bar to satisfy the test is the criteria to judge the data good or bad.

Both the area and the point-to-point thermodynamic consistency tests ${ }^{(6)}$ were applied. In the point to point test, one must have enough data points on one isotherm to regress a polynomial out of the $\ln \gamma_{i}$ versus $x$ curve. Next, an overall criterion for acceptance or rejection of data set needs to be set based on the cumulative errors for all the data points summed together, as it is expected that singular data points are likely to exhibit varying deviations. The area test by its very nature involves cumulative errors for the data points within an isotherm. Also if one want to perform this test strictly, he must have the infinite dilution data on both ends which is quite difficult to obtain. In our case, we have only seven data points on each isotherm, also we do not have the infinite dilution data, so both the point to pint and the area tests cannot be performed strictly. Nevertheless, as it is done in literature, we plot the $\ln \gamma_{1}$ versus $x_{1}$ and the $\ln \gamma_{2}$ versus $x_{1}$

curves in the point to point test and plot the $\ln \frac{\gamma_{1}}{\gamma_{2}}$ versus $x_{1}$ curve for the area test, then we just simply judge if the two tests are satisfied by visual observation. Table 8 and 9 give the thermodynamic consistency test result for $310^{\circ} \mathrm{C}$ and $340^{\circ} \mathrm{C}$ isotherms respectively, Figures 21 and 22 show their corresponding point to point tests. Figure 20 shows the area test. 
Table 8 . Thermodynamic consistency test result for $310^{\circ} \mathrm{C}$ Isotherm

\begin{tabular}{|l|l|l|l|l|l|l|}
\hline$X_{\text {ethylbenzene }}$ & $\gamma_{1}$ & $\gamma_{2}$ & $\ln \frac{\gamma_{1}}{\gamma_{2}}$ & $\ln \gamma_{1}$ & $\ln \gamma_{2}$ & $G^{\mathrm{E}}(\mathrm{J} / \mathrm{mol})$ \\
\hline 0.019189 & 2.3174 & 0.9997 & 0.84075 & 0.84045 & -0.0003 & 76.776 \\
\hline 0.1707 & 1.5207 & 1.0001 & 0.41907 & 0.41917 & 0.00001 & 347.31 \\
\hline 0.3028 & 1.3199 & 1.0236 & 0.25423 & 0.27756 & 0.023326 & 486.32 \\
\hline 0.4289 & 1.2023 & 1.0767 & 0.11034 & 0.18424 & 0.073901 & 588.13 \\
\hline 0.6153 & 1.0859 & 1.2716 & -0.15787 & 0.082409 & 0.24028 & 694.11 \\
\hline 0.7823 & 1.0273 & 1.5495 & -0.4110 & 0.026934 & 0.43793 & 564.58 \\
\hline 0.9535 & 1.0019 & 2.0938 & -0.73708 & 0.001898 & 0.73898 & 175.38 \\
\hline
\end{tabular}

Table 9. Thermodynamic consistency test result for the $340^{\circ} \mathrm{C}$ Isotherm

\begin{tabular}{|l|l|l|l|l|l|l|}
\hline $\mathrm{X}_{\text {ethylbenzene }}$ & $\gamma_{1}$ & $\gamma_{2}$ & $\ln \frac{\gamma_{1}}{\gamma_{2}}$ & $\ln \gamma_{1}$ & $\ln \gamma_{2}$ & $\mathrm{G}^{\mathrm{E}}$ \\
& & & & & & $(\mathrm{J} / \mathrm{mol})$ \\
\hline 0.034 & 1.9587 & 0.9956 & 0.67669 & 0.67228 & -0.00441 & 94.822 \\
\hline 0.1757 & 1.4234 & 0.9992 & 0.35385 & 0.35305 & -0.0008 & 312.85 \\
\hline 0.2774 & 1.2842 & 1.015 & 0.23525 & 0.25014 & 0.014889 & 408.63 \\
\hline 0.4400 & 1.1581 & 1.0787 & 0.071024 & 0.14678 & 0.075757 & 545.49 \\
\hline
\end{tabular}


Table 9. Thermodynamic consistency test result for the $340^{\circ} \mathrm{C}$ Isotherm (continued)

\begin{tabular}{|l|l|l|l|l|l|l|}
\hline $\mathrm{X}_{\text {ethylbenzene }}$ & $\gamma_{1}$ & $\gamma_{2}$ & $\ln \frac{\gamma_{1}}{\gamma_{2}}$ & $\ln \gamma_{1}$ & $\ln \gamma_{2}$ & $\mathrm{G}^{\mathrm{E}}$ \\
\hline 0.6226 & 1.0726 & 1.2357 & -0.14155 & 0.070086 & 0.21164 & 629.71 \\
\hline 0.7758 & 1.0221 & 1.4473 & -0.34784 & 0.021859 & 0.3697 & 508.98 \\
\hline 0.9373 & 0.9938 & 1.8829 & -0.63903 & -0.00622 & 0.63281 & 172.55 \\
\hline
\end{tabular}

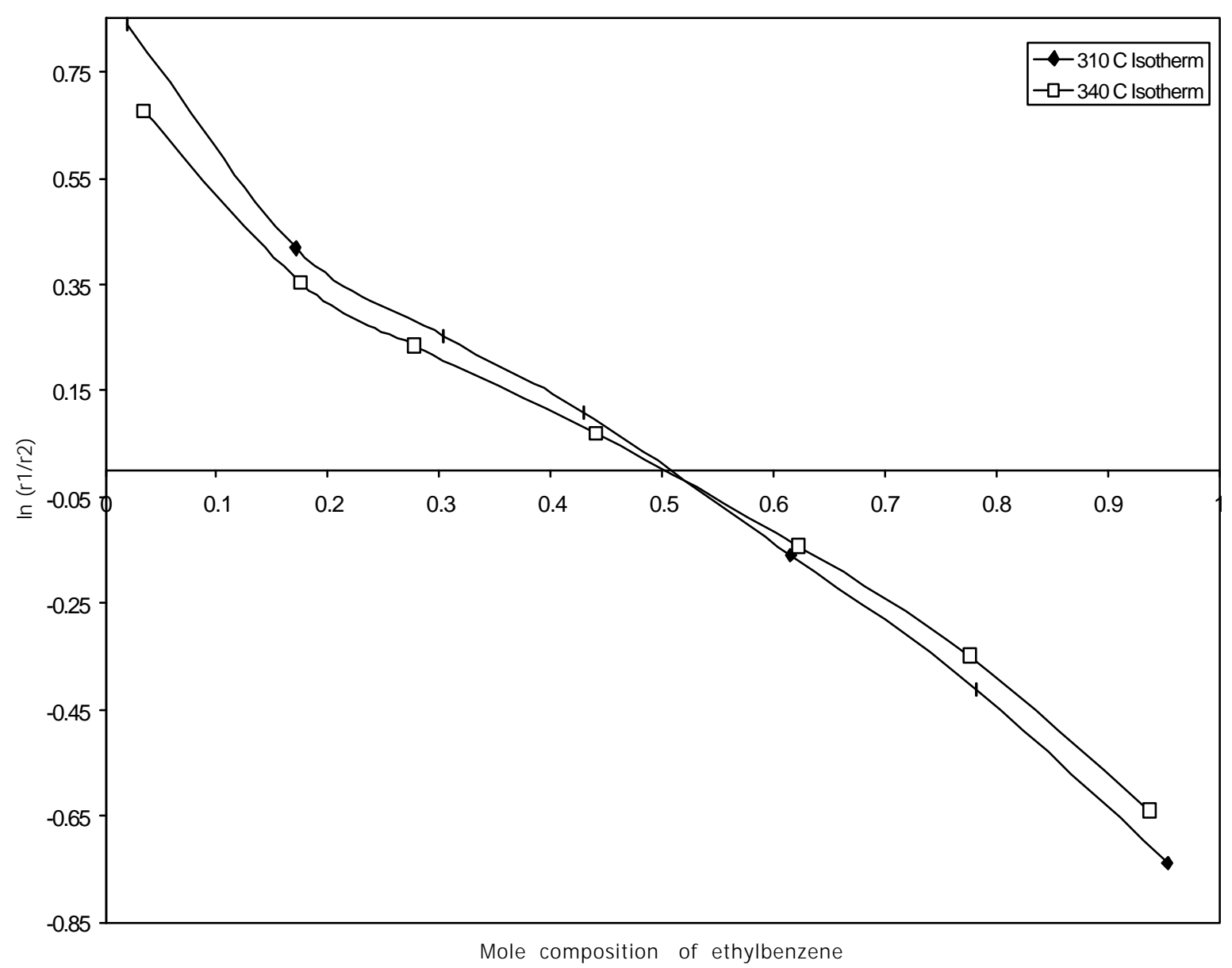

Figure 20. Thermodynamic area consistency test for $310^{\circ} \mathrm{C}$ and $340^{\circ} \mathrm{C}$ isotherms 


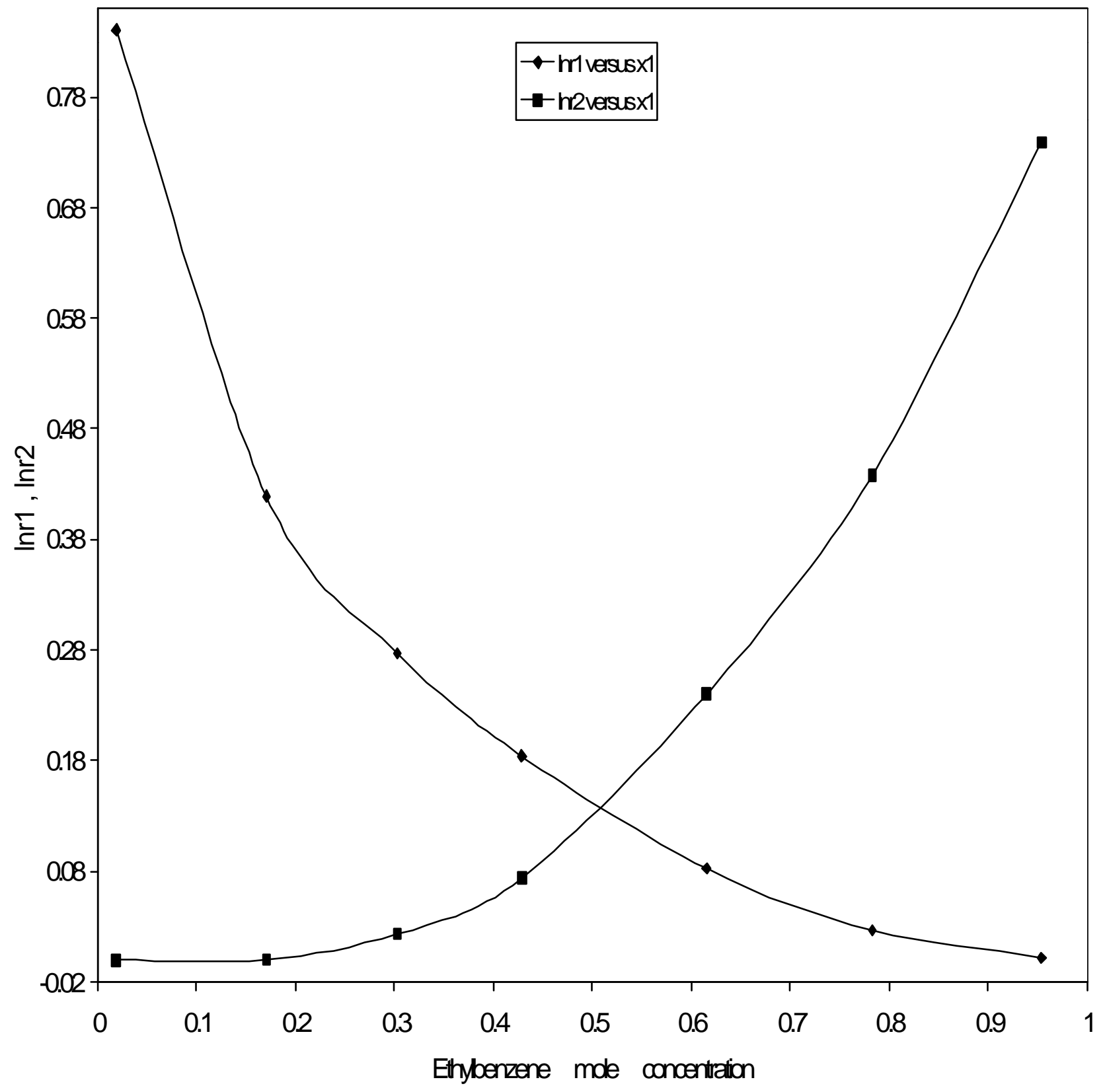

Figure 21 Thermodynamic point to point consistency test on $310^{\circ} \mathrm{C}$ isotherm 


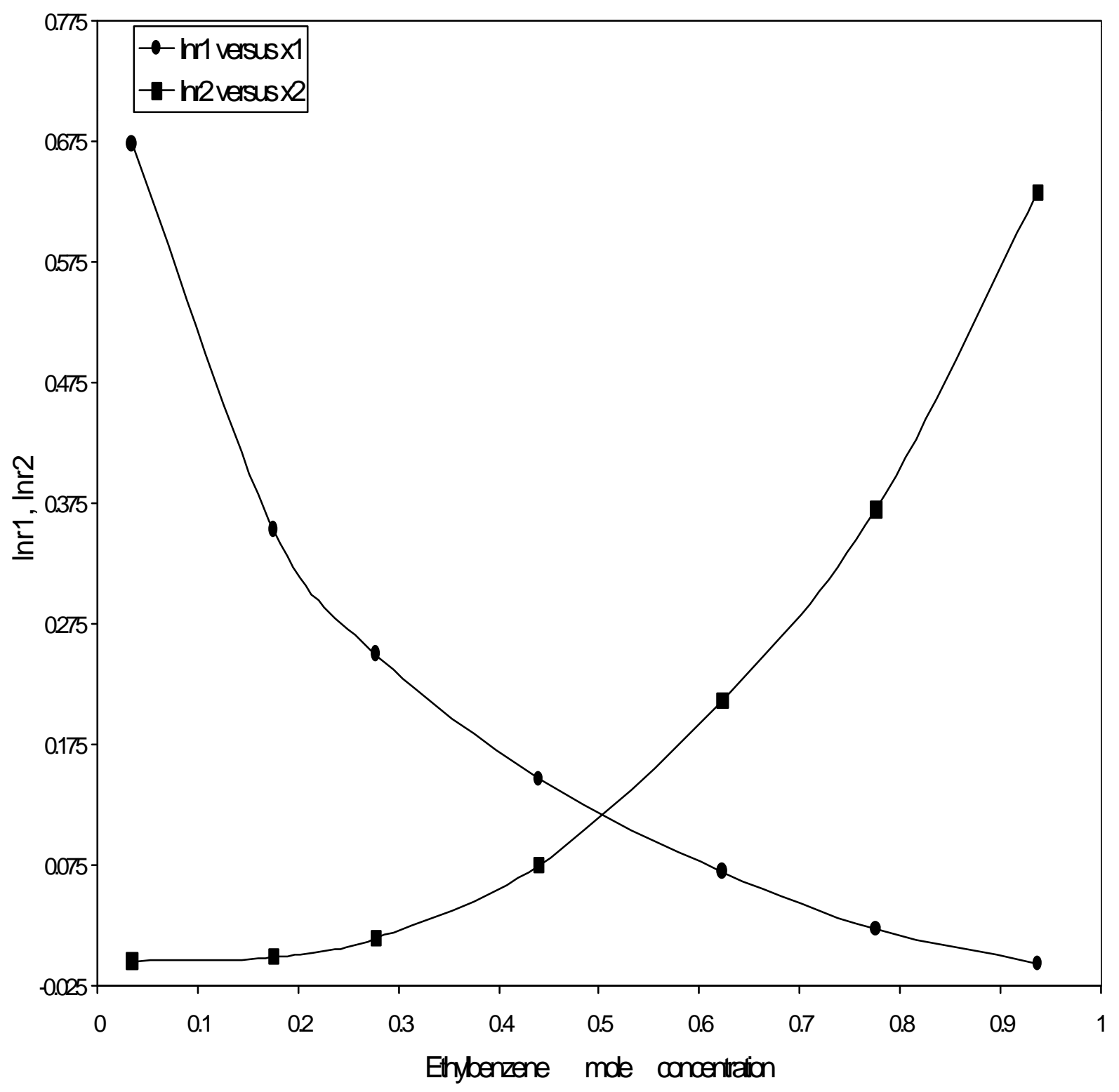

Figure 22 Thermodynamic point to point consistency test on the $340^{\circ} \mathrm{C}$ isotherm 
From Figure 20 through Figure 22, we can notice that for both $310^{\circ} \mathrm{C}$ and $340^{\circ} \mathrm{C}$ isotherms, both the point to point and area thermodynamic consistency tests can be satisfied, Figure 23 illustrates the $\mathrm{G}^{\mathrm{E}}$ data generated from the VLE data.

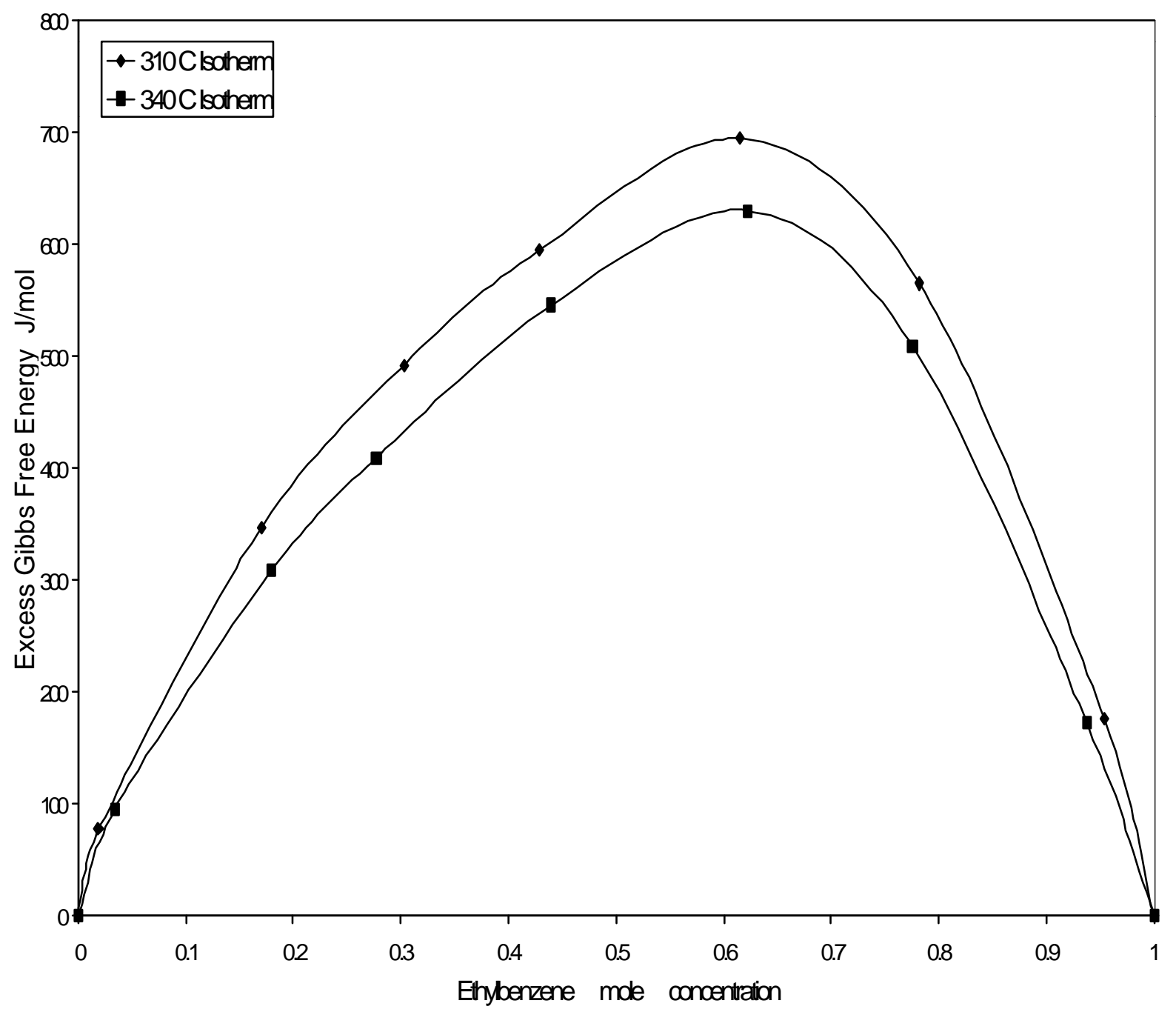

Figure 23 Excess Gibbs Free Energy of ethylbenzene-quinoline system at $310^{\circ} \mathrm{C}$ and $340^{\circ} \mathrm{C}$ 


\section{References:}

1. Kabadi, V.N., Thermodynamic Model for Calorimetric and Phase Coexistence Properties of Coal Derived Fluids, Final Technical Repot, October 1, 1992.

2. $\quad$ Niesen, V.G. and V.F. Yesavage, J. Chem. Eng. Data, 33, 253, 1988.

3. AL-Ghamdi, A.M., Thesis for M.S. Department of Chemical Engineering, North Carolina A\&T State University, 1996.

4. Ambrose, D. J., Chem. Thermodynamics, 19, 1007-1008, 1987.

5. Viswanath, D.S., American Petroleum Institute Monogragh Series-Quinoline.

6. Prausnitz, J.M., Lichtenthaler, R.N. and Gomes de Azevedo, E., "Molecular Thermodynamics of Fluid-Phase Equilibria", $3^{\text {rd }}$ Edition, Prentice-Hall, 1999. 